\title{
The Slightly-Enriched Spectral Shift Control Reactor
}

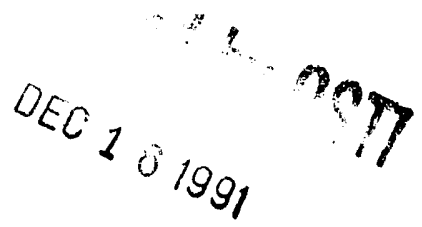

Final Report for the Project

September 30, 1988 - September 30, 1991

\author{
Co-principal Investigators \\ William R. Martin \\ John C. Lee \\ Edward W. Larsen \\ Milton C. Edlund* \\ Research Assistants \\ Robert E. Grove \\ Paul M. Keller \\ Amitava Majumdar \\ Abdelaziz Oukebdane \\ Dorde Tomasevic \\ Moaied Miften \\ Department of Nuclear Engineering \\ The University of Michigan \\ Ann Arbor, Michigan 48109-2104 \\ *Department of Mechanical and Nuclear Engineering \\ Virginia Polytechnic Institute and State University \\ Blacksburg, Virginia
}

November, 1991

This report was prepared as an account of work sponsored by the United States Government. Neither the United States nor the Department of Energy, nor any of their employees, nor any of their contractors, subcontractors, or their employees, makes any warranty, express or implied, or assumes any legal liability or responsibility for the accuracy, completeness, or usefulness of any information, apparatus, product or process disclosed or represents that its use would not infringe privately-owned rights.

Prepared for

THE U. S. DEPARTMENT OF ENERGY

AGREEMENT NO. DE-FG07-88ER-12809

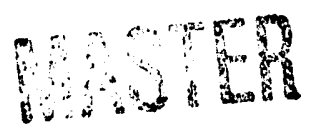




\begin{abstract}
An advanced converter reactor design utilizing mechanical spectral shift control rods in a conventional pressirized water reactor configuration is under investigation. The design is based on the principle that a harder spectrum during the early part of the fuel cycle will result in larger neutron captures in fertile ${ }^{238} \mathrm{U}$, which can then be burned in situ in a softer spectrun later in the cycle. Preliminary design calculations performed during FY 89 showed that the slightly-enriched spectral shift reactor design offers the benefit of substantially increased fuel resource utilization with the proven safety characteristics of the pressurized water reactor technology retained. Optimization of the fuel design and development of fuel management strategies were carried out in FY 90, along with effort to develop and validate neutronic methodology for tight-lattice configurations with hard spectra. During FY 91, the final year of the grant, the final SESSR design was determined, and reference design analyses were performed for the assemblies as well as the global core configuration, both at the beginning of cycle (BOC) and with depletion. The final SESSR design results in approximately a $20 \%$ increase in the utilization of uranium resources, based on equilibrium fuel cycle analyses. Acceptable pin power peaking is obtained with the final core design, with assembly peaking factors equal to less than 1.04 for spectral shift control rods both inserted and withdrawn, and global peaking factors at BOC predicted to be 1.4. In addition, a negative MTC is maintained for BOC, which is difficult to achieve with conventional advanced converter designs based on a closed fuel cycle. The SESSR design avoids the need for burnable poison absorber, although they could be added if desired to increase the cycle length while maintaining a negative MTC. A number of challenging reactor physics questions remain, including the treatment of resonance absorption in tight lattice reactors such as the SESSR and the optimai control of SSCRs throughout the fuel cycle to optimize the production and subsequent burnup of plutonium.
\end{abstract}




\title{
Table of Contents
}

\begin{abstract}

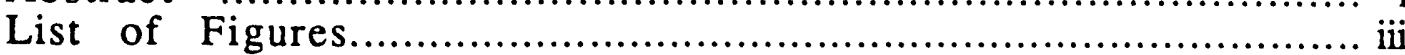

List of Tables................................................................................... ii

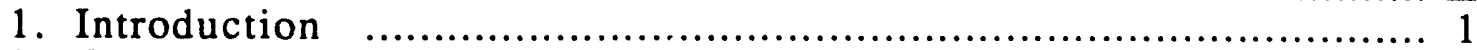

2. Objectives of the Research ....................................................... 3

3. Overall Scope of the Project ................................................... 4

4. Design and Analysis of an SESSR Configuration (Task 1) ....................... 7

4.1. Selection of the SESSR Assembly Design ................................ 7

4.1.1. Effect of $F / M$........................................................... 7

4.1.2. Effect of Enrichment …….............................................. 9

4.1.3. Use of Mixed-Oxide Fuels ...................................................... 10

4.2. Reference SESSR Design …….......................................... 10

4.2.1. SESSR Assembly Design ......................................... 11

4.2.2. Global SESSR Analysis at BOC ............................................ 14

4.3 Thermal-hydraulic Analysis ........................................... 17

4.4. Fuel Cycle Calculations …............................................ 23

4.5. BOC Reactivity Parameters................................................... 27

4.6. Global Depletion Analysis of the SESSR …............................. 28

4.6.1. Global Depletion Analysis Methods ……….......................... 30

4.6.2. SESSR Global Depletion Results ........................................ 33

5. Methods Development for SESSR Analysis (Task 2) .............................. 34

5.1. Validation of the CPM-2 Code ...................................... 36

5.1.1. Simulation of the PROTEUS Critical Experiments ......................... 36

5.1.2. Comparison with the VIM Monte Carlo Code ............................. 37

5.1.3. Comparison with the CASMO-3 Code................................... 39

5.2. Generation of Reflector Cross Sections ................................. 42

5.3. Development of a Fuel Cycle Code (CYCLE) ………................... 43

5.4. Lumped Fission Product Correlation for UMLEO ............................4 45

5.5. Improved Resonance Absorption Models for the SESSR ………..... 45

5.5.1. CPM-2 Approach ................................................... 46

5.5.2. Multiband Method for Resolved Resonances .............................. 46

5.5.3. Hybrid Monte Carlo/Collision Probability Methods ..................... 48

5.5.4. Improved Cross Section Library for CPM-2 ………………...... 48

5.5.5. Improved Version of VIM ................................................... 49

5.6. Improved Collision Probability Method for CPM-2 ....................... 50

5.7. Improved Global Analysis Capability ....................................... 50

5.8. Implementation of CPM-2 on Advanced Computer Architectures....... 53

5.9. Development of Global CPM-2 Capability .................................. 54

5.10. Global Depletion Method ….......................................... 54

5.11. Optimal Fuel Depletion Strategy …….............................. 54

6. Verification of SESSR Design for PWR Use (Task 3) ............................ 55

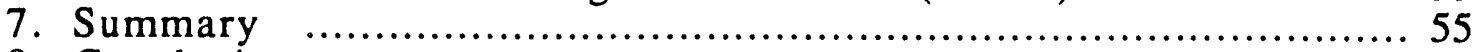

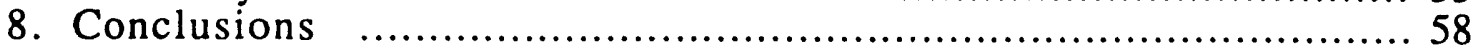

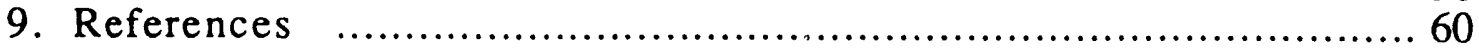

Appendix A. CASMO3-CPM2 Comparisons for Spectral Shift Lattices........ 63 


\section{List of Figures}

Figure 1. Assembly Average Spectra at BOC - SSC Rods Inserted and Withdrawn...... 4

Figure 2. Specific Tasks for the Overall Project...................................... 6

Figure 3. Cycle Length Increase, BOC $k_{\infty}$, and Assembly Pressure Drop vs. F/M...... 9

Figure 4. 17x17 SESSR Reference Assembly................................... 11

Figure 5. Assembly Pin Power Distributions.................................... 13

Figure 6. SESSR Loading Pattern (1/8 Core).................................... 14

Figure 7. SESSR BOC Hot Full Power Relative Core Power Map...................... 15

Iigure 8. Assembly $\mathrm{k}_{\infty}$ and Fissile Nuclide Inventory vs. Assembly Burnup.......... 24

Figure 9. SESSR Core Design and Relative Core Power Map......................... 35

Figure 10. Idealized (4×4) Lattice for Assembly-level Comparison...................... 39

Figure 11. Relative Core Power Map for Millstone Unit 3............................. 44

Figure 12. CASTOR and UM2DB Core Power Distributions for Biblis-1300........... 52

\section{List of Tables}

Table I. Effect of Fuel-to-Moderator Ratios on Cycle Length for 2.5 w/o Assemblies 8

Table II. Selected Core Parameters.......................................... 12

Table III. Comparison of Thermal-Hydraulic Parameters.............................. 20

Table IV. Design Parameters for the SESSR...................................... 22

Table V. Batch Core Cycle Length.............................................. 25

Table VI. Equilibrium Core Cycle Length......................................... 26

Table VII. Estimated Fuel Costs and Conversion Ratios............................... 27

Table VIII. BOC Reactivity Parameters............................................. 29

Table IX. Comparison of the CPM-2 and VIM Computer Codes........................ 38

Table X. Comparison of VIM and CPM-2 with Increased Numiver of Spatial Regions 39

Table XI. Comparison of CASMO-3 and CPM-2................................ 41 


\section{Introduction}

Under Department of Energy Grant DE-FG07-88ER12809, effort was begun at the University of Michigan in September, 1988, to examine an advanced converter reactor (ACR) design utilizing a spectral shift control (SSC) concept. The particular ACR design under study involves implementation of a mechanical spectral shift concept in a conventional pressurized water reactor (PWR) configuration. The slightly-enriched spectral shift reactor (SESSR) design offers the benefit of substantially increased fuel resource utilization while retaining the proven safety characteristics of the PWR technology. This report summarizes the results of this research project from its inception in 1988 through completion in 1991. To the extent possible, this is a comprehensive report of our efforts during the course of this project, but includes only brief summaries of efforts reported in detail in progress reports [1-3]. The remainder of this section describes the spectral shift concept and the overall SESSR project.

The mechanical spectral shift concept was first suggested by Edlund in 1975 [4] and is based on the principle that a harder spectrum will result in increased neutron captures in fertile ${ }^{238} \mathrm{U}$, thereby producing more plutonium, which can be burned in situ in a softer spectrum later in the fuel cycle. This results in a substantially higher conversion ratio and increased utilization of uranium resources compared with typical light water reactor (LWR) fuel cycles. The spectral hardening is achieved through increasing the fuel-to-moderator volume ratio (F/M) by insertion of mechanical spectral shift control rods (SSCRs) in a tight lattice compatible with existing PWR pressure vessels. Several substantial projects [5-8] with similar objectives are underway overseas. These projects are mostly based on a closed fuel cycle, with tight lattice designs, and utilize high fissile enrichment in the range of $\sim 6-12 \%$ by weight (w/o), which can lead to a longer cycle but at the possible expense of a positive moderator temperature coefficient (MTC) of reactivity. In contrast, we have investigated the utilization of fuel enrichments of $\sim 2-3 \mathrm{w} / \mathrm{o}$, with semi-tight lattice designs, 
which allows us to retain the excellent safety characteristics of conventional PWR designs, including a negative MTC at all times in the cycle. The importance of maintaining a negative MTC appears to be emphasized in more recent ACR studies [8], where F/Ms closer to those of our SESSR design have been considered.

The initial phases of our project concentrated on selection of key neutronic parameters, preliminary analyses of SESSR core configurations, and limited validation of neutronic analysis codes and methodology. This effort was described in the first two progress reports [1-2]. The third year's effort focused on improving and optimizing the SESSR design and continuing the effort to develop accurate and efficieri methodology for tight-lattice SESSR analysis. In addition, the SESSR design was finalized and global power distributions were obtained as well as some global depletion results. In addition, effort was expended to develop and verify analytical and computational methods for the analysis of tight-lattice LWR configurations. A substantial portion of the third-year effort was reported in a recent progress report [3], the contents of which have been incorporated into this report with appropriate modifications to account for results obtained since the progress report was issued in May 1991. Therefore, this report supersedes and replaces Ref. 3. However, the current report does not attempt to duplicate the contents of the first two progress reports [1-2], but instead summarizes the salient details of our efforts during the first two years of the project. Therefore, the reader may need to refer to parts of the previous reports for details regarding a specific task.

The next section discusses the objectives of the SESSR project and the following section gives the overall scope of the project, including a broad overview of the project tasks. These sections are followed by a detailed presentation of the work carried out during the past three years on the SESSR project. 


\section{Objectives of the Research}

The overall objective of our project is to investigate the feasibility of the SESSR as a spectral shift concept, examining the implications of this design from the standpoint of reactor physics, thermal-hydraulics, safety, and economic issues. Since the reactor physics analysis of any spectral shift reactor (SSR), including the SESSR, presents several computational challenges to currently available LWR analysis tools, we have also undertaken efforts to develop and validate analytical and computational methods for analyzing the tight-lattice LWR configurations which characterize all SSR concepts.

As presented in the original proposal to the Department of Energy (DOE) and subsequent proposals submitted for the continuing effort, the specific objectives of the research project can be summarized as follows:

- To investigate fuel burnup and cycle length of the SESSR design,

- To analyze reactor physics characteristics of the tight-lattice SESSR concept,

- To compare the SESSR concept with the conventional SSR concept using a closed fuel cycle, including fuel cycle costs, MTC, reactivity control, kinetic behavior, thermal-hydraulic limits, and safety analysis,

- To develop improved deterministic transport methods for assembly-level flux spectrum and depletion analysis for tight-lattice LWR configurations,

- To develop improved coarse-mesh methods for the whole-core reactor calculations that are needed to evaluate alternative fuel loading strategies,

- To develop systematic algorithms for determining optimum fuel loading and spectral shift control strategy in fuel cycle analysis, and

- To develop a detailed mechanical and T/H design of a tight lattice SESSR assembly and confirm its use in an existing PWR plant currently under construction.

The following sections present the results of the effort over the three-year duration of the project to achieve these objectives. 


\section{Overall Scope of the Project}

The basic idea of the SSC concept is to change the $\mathrm{F} / \mathrm{M}$ during reactor operation. During the initial portion of a fuel cycle, the SSCRs are inserted into the core to displace water, hence increasing the F/M considerably above that of typical LWR designs. Following enhanced production of plutonium in the resultant hard neutron spectrum, the SSCRs are gradually withdrawn, softening the spectrum and enhancing the burnup of the bred plutonium later in the cycle. Figure 1 illustrates the spectral shifts associated with insertion and withdrawal of the SSCRs, and the effect on the spectrum is seen to be quite large. It should be noted that the assembly power is being held constant in Figure 1.

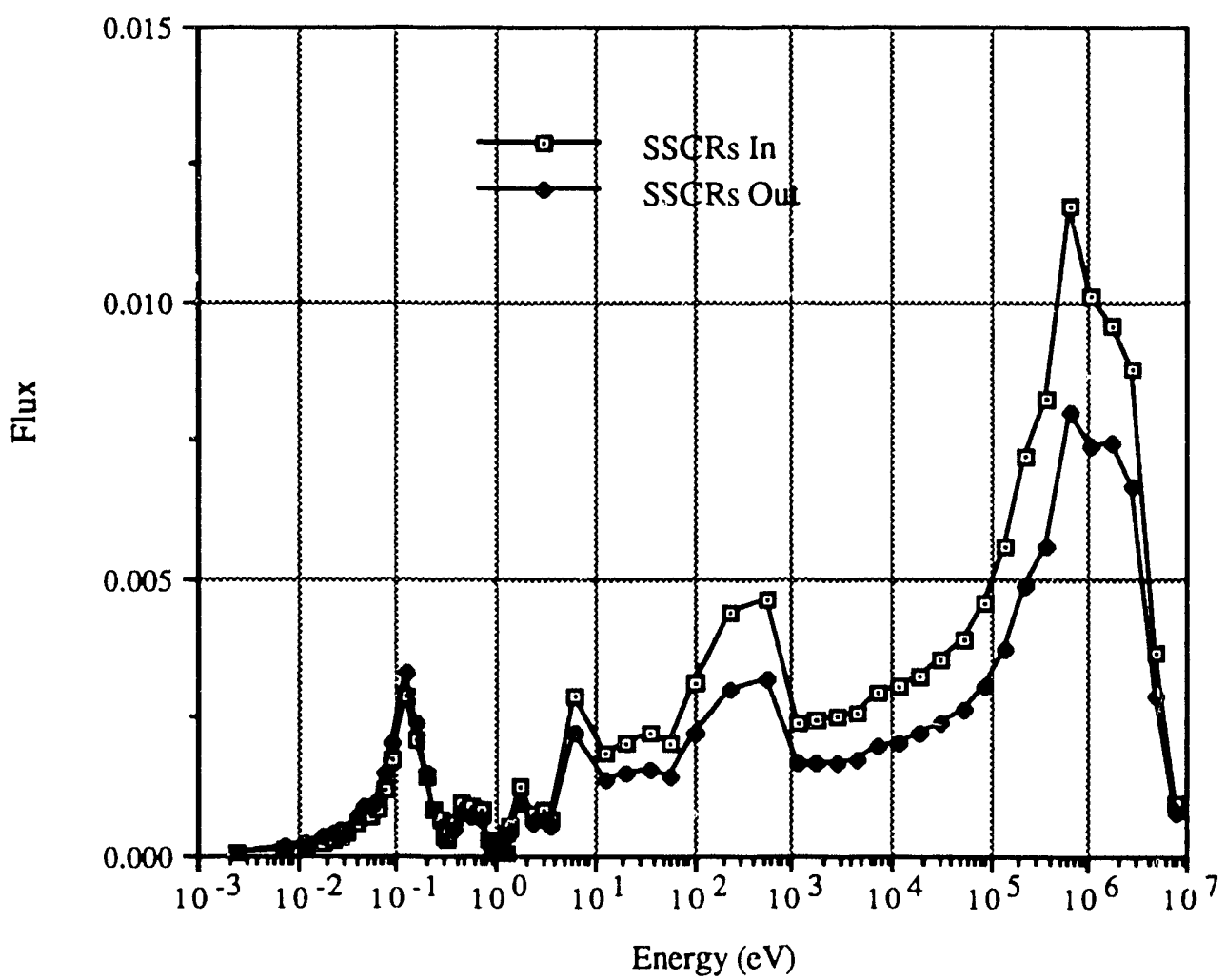

Figure 1. Assembly Average Spectra at BOC - SSC Rods Inserted and Withdrawn 
The SESSR concept under study has the potential to offer significant savings in the fuel cycle cost and improvement in uranium utilization without sacrificing the proven safety characteristics of conventional PWR technology. Since the use of burnable neutron absorbers can be avoided with the introduction of SSCRs, improvements in the neutron economy and fuel cycle cost are possible. To establish the viability of the SESSR concept as an ACR design and assess its performance with respect to conventional PWR designs, three broad categories of tasks were proposed in our original proposal:

Task 1. Design and analysis of an SESSR configuration compatible with an existing PWR plant design,

Task 2. Development and validation of calculational methods to carry out the reactor physics and fuel cycle analysis of the SESSR design, and

Task 3. Substantiation of the design concept and evaluation of its compatibility with a standard PWR design with the assistance of B\&W Fuel Company.

During the first year, an emphasis was placed on Task 1 in order to establish early in the project a preliminary nuclear design that could demonstrate the viability of the SESSR concept. These studies included unit-cell, unit-assembly, and global neutronic calculations to examine a number of feasible SSCR designs and lattice configurations. This work was extended during the second year to include detailed parametric studies, fuel cycle calculations (including equilibrium cycle studies), and the continuing effort to perform global calculations, including the treatment of reflectors, fuel depletion, SSCR movement, and fuel shuffling. This second year effort identified the principal areas of analysis uncertainty due to the tight-lattice configuration, and effort was continued into the third year to address these issues. Task 3 , the verification by B\&W Fuel Company of our SESSR design for eventual PWR deployment, was deferred due to changing priorities and was 
replaced by a detailed comparison of the neutronics methods used by B\&W to those utilized for the SESSR analysis.

Sections 4-6 below discuss the results of our efforts on Tasks 1-3, respectively, over the course of the project. Figure 2 summarizes the specific items that were included in each task, as delineated in the original and subsequent proposals for the SESSR project. These tasks are discussed in the following sections as parts of larger topics and there is no attempt to single out specific tasks in the general discussion that follows. However, Section 7 itemizes each of the tasks contained in Figure 2 and summarizes our curresponding efforts.

Task 1. Design and analysis of a SESSR configuration

1.1. Nuclear design of the SESSR fuel assembly

1.2. Global core analysis of the SESSR concept

1.3. Thermal-hydraulic analysis

1.4. Fuel cycle cost analysis

Task 2. Methods development for SESSR analysis

2.1. CPM-2 effort

2.1.1. Comparison with critical experiments

2.1.2. Fission product model

2.1.3. Triangular lattice capability

2.1.4. Improved collision probability calculation

2.1.5. Comparison with the VIM Monte Carlo Code

2.1.6. Comparison with the CASMO-3 Code

2.2. UMLEO effort

2.3. UM2DB and UM3DB effort

2.4. Improved resonance absorption models

2.5. Improved coarse mesh capability

2.6. Optimal fuel depletion strategy

Task 3. Verification of SESSR design for PWR use (B\&W)

Figure 2. Specific Tasks for the Overall Project 


\section{Design and Analysis of an SESSR Configuration (Task 1)}

4.1. Selection of the SESSR Assembly Design. One of our primary objectives has been the determination of a reference SESSR assembly design that could be used for the final design studies. This effort involved a large number of parametric studies to investigate the interplay between $F / M$, the number and arrangement of SSCRs, fuel enrichment, and fuel rod radius, and, for comparison, the use of mixed oxide fuels. These analyses were performed on the SESSR assembly and are summarized in the remainder of this section. Following the assembly-level design optimization, Sections 4.2 through 4.6 will discuss the global SESSR analyses which include single-channel thermal-hydraulic $(\mathrm{T} / \mathrm{H})$ analyses as well as global depletion calculations.

4.1.1. Effect of F/M. As discussed in the previous reports [1-3], the assembly F/M plays the crucial role in determining the overall performance of the SSC concept. At BOC, the $\mathrm{F} / \mathrm{M}$ affects the rate of plutonium production and at EOC it determines the extent to which the bred plutonium is depleted. Since its variation during the cycle (via SSCR movement) determines the tradeoff between these reaction rates, we have performed our parameter studies by varying the $\mathrm{BOC}$ and $\mathrm{EOC} \mathrm{F/Ms,} \mathrm{which} \mathrm{in} \mathrm{turn} \mathrm{are} \mathrm{determined} \mathrm{by} \mathrm{the}$ number of SSCRs and the fuel pin pitch. That is, the BOC F/M is based on all SSCRs inserted and the EOC F/M is based on all SSCRs withdrawn. For these calculations, the SSCR guide tubes are assumed to have an outer diameter equal to the pitch. A simple $T / H$ analysis was performed to obtain the assembly pressure drops. Depletion analyses were performed using the CPM-2 code [9] and the results transmitted to the CYCLE code [2], which was used to determine the batch cycle length. These codes and others used in our analyses will be discussed in later sections.

The cycle length comparisons include percentage increases in batch cycle length for each fuel design for SSCRs "in" versus SSCRs "out". We have defined this to be the spectral shift advantage for a specific fuel design. The results are tabulated in Table I and 
shown graphically in a contour plot in Figure 3. The contour lines on this plot represent surfaces of equal cycle length increase. The other lines are constant $B O C \mathrm{k}_{\infty}$ and constant assembly pressure drop lines. The parametric cases of Table I are shown as points with the corresponding case numbers in Figure 3.

Table I. Effect of Fuel-to-Moderator Ratios on Cycle Length for 2.5 w/o Assemblies

\begin{tabular}{|c|c|c|c|c|c|c|c|c|c|}
\hline \multirow{3}{*}{ Case } & & & & & & & \multicolumn{2}{|c|}{$\begin{array}{l}\text { Cycle Length } \\
(\mathrm{MWd} / \mathrm{kg} \mathrm{U})\end{array}$} & \multirow{3}{*}{$\begin{array}{c}\text { \% Increase } \\
\text { Due to } \\
\text { Spectral } \\
\text { Shift }\end{array}$} \\
\hline & \multicolumn{2}{|c|}{$\begin{array}{l}\text { Fuel to Moderator } \\
\text { Ratio }\end{array}$} & \multirow{2}{*}{$\begin{array}{l}\text { Number } \\
\text { of } \\
\text { SSCRs }\end{array}$} & \multirow{2}{*}{$\begin{array}{l}\text { Pin Cell } \\
\text { Pitch } \\
(\mathrm{mm})\end{array}$} & \multirow{2}{*}{$\begin{array}{l}\text { Pressure } \\
\text { Drop } \\
\text { (MPa) }\end{array}$} & \multirow{2}{*}{$\begin{array}{l}\text { Number } \\
\text { of Fuel } \\
\text { Rods } \\
\text { in Core }\end{array}$} & \multirow[t]{2}{*}{ SESSR } & \multirow{2}{*}{$\begin{array}{c}\text { SESSR } \\
\text { SSCRS } \\
\text { Out }\end{array}$} & \\
\hline & $\begin{array}{l}\text { SSCRs } \\
\text { Inserted } \\
\text { (BOC) }\end{array}$ & $\begin{array}{c}\text { SSCRs } \\
\text { Withdrawn } \\
\text { (EOC) }\end{array}$ & & & & & & & \\
\hline 1 & 0.900 & 0.540 & 96 & 10.82 & 0.17 & 56256 & 21.2 & 17.8 & 19.1 \\
\hline 2 & 0.850 & 0.540 & 88 & 11.02 & 0.14 & 55400 & 21.2 & 17.8 & 19.1 \\
\hline 3 & 0.850 & 0.495 & 104 & 10.89 & 0.18 & 50968 & 22.0 & 17.9 & 22.9 \\
\hline 4 & 0.850 & 0.463 & 116 & 10.77 & 0.21 & 50396 & 22.3 & 17.9 & 24.6 \\
\hline 5 & 0.812 & 0.543 & 80 & 11.20 & 0.11 & 55952 & 21.1 & 17.8 & 18.5 \\
\hline 6 & 0.813 & 0.499 & 96 & 11.07 & 0.14 & 53184 & 22.0 & 17.9 & 22.9 \\
\hline 7 & 0.812 & 0.457 & 112 & 10.93 & 0.18 & 48752 & 22.5 & 17.9 & 25.7 \\
\hline 8 & 0.813 & 0.417 & 128 & 10.76 & 0.24 & 46880 & 23.1 & 18.1 & 27.6 \\
\hline 9 & 0.700 & 0.498 & 72 & 11.68 & 0.08 & 52056 & 21.5 & 18.3 & 17.5 \\
\hline 10 & 0.700 & 0.460 & 88 & 11.56 & 0.10 & 49000 & 22.1 & 18.2 & 21.4 \\
\hline 11 & 0.700 & 0.423 & 104 & 11.42 & 0.11 & 48024 & 23.5 & 18.8 & 25.0 \\
\hline 12 & 0.580 & 0.462 & 52 & 12.43 & 0.05 & 52156 & 21.1 & 18.7 & 12.8 \\
\hline 13 & 0.580 & 0.422 & 72 & 12.29 & 0.06 & 47736 & 21.9 & 18.7 & 17.1 \\
\hline 14 & $0.790^{*}$ & $0.509^{*}$ & $88^{*}$ & $11.21^{*}$ & $0.12^{*}$ & 53800 & $22.2^{*}$ & $18.6^{*}$ & $19.9^{*}$ \\
\hline
\end{tabular}

* Reference design.

When examining Figure 3, it should be kept in mind that the neutronic parameters held constant for these cases were fuel rod diameter and enrichment. Hence, as shown in Table I, the number of fuel rods is changing as well as the pitch and number of SSCRs. It should also be noted that the spectral shift advantage increases as one moves down and to the right on the contour plot from Case 5, but the pressure drop also increases quickly, which poses thermal-hydraulic and safety concerns. Therefore, if one moves down and to the left, following an "isobar" (in pressure drop), the spectral shift advantage increases 
with little increase in the pressure drop. However, the number of fuel rods decreases as one moves down the isobars, resilting in an increase in the linear heat generation rate, which can lead to unacceptable power peaking factors. Another potential disadvantage is the increased $k_{\infty}$ at BOC. This must be compensated for by increasing the soluble boron concentration, which in turn will increase the tendency for a positive MTC at BOC. All of these factors were taken into account for our final design choice, which is discussed in Section 4.2 .1 below.

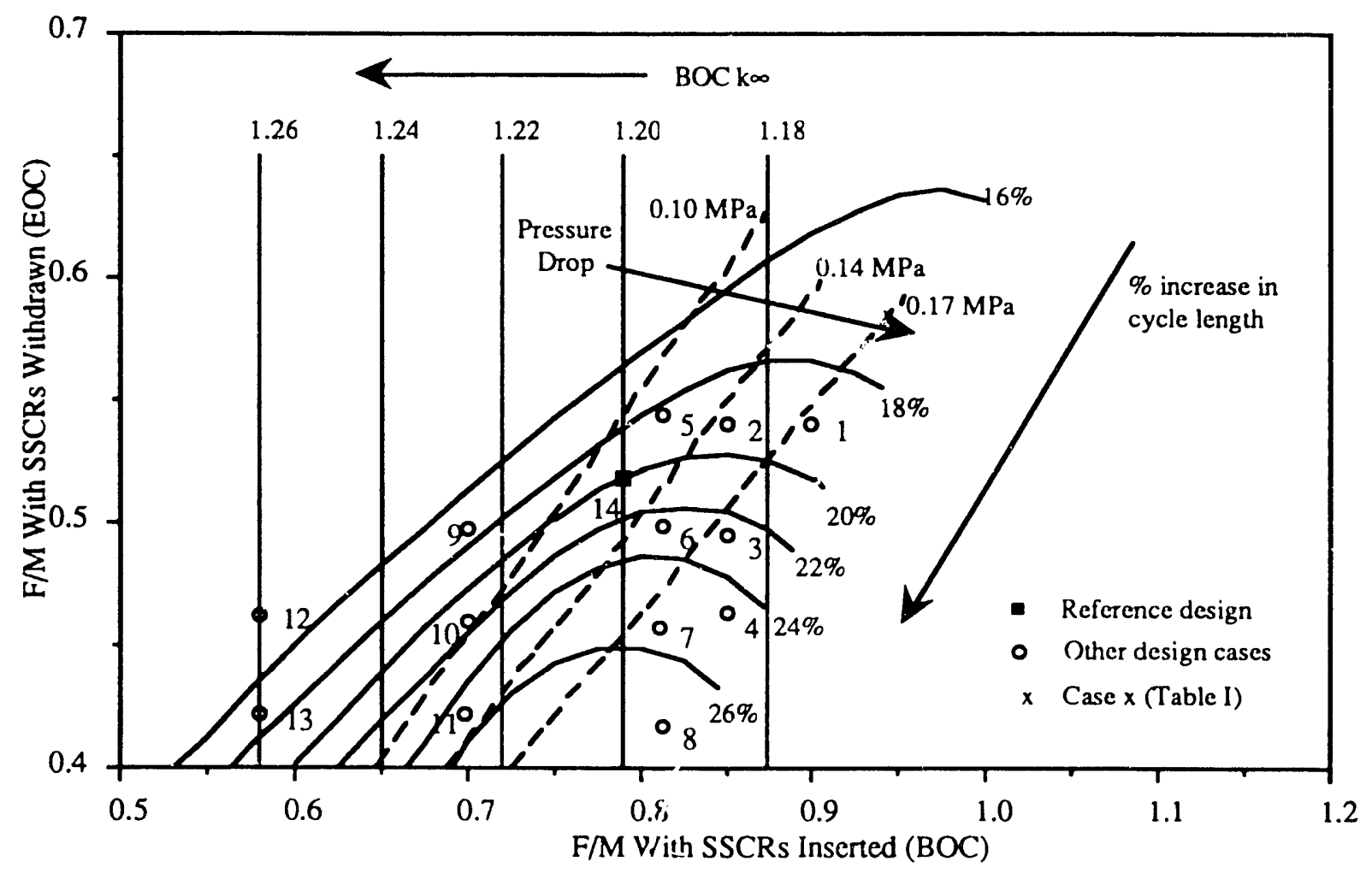

Figure 3. Cycle Length Inciease, BOC $k_{\infty}$, and Assembly Pressure Drop vs. F/M

4.1.2. Effect of Enrichment. An earlier report examined the effect of enrichment on the spectral shift advantage, cycle length, and uranium utilization [2]. It was found that the spectral shift advantage is fairly insensitive to enrichment, although there is a noticeable but slight decrease with increasing enrichment. This occurs because high enrichment 
assemblies already have a relatively hard spectrum compared with lower enrichment assemblies and the relative effect of withdrawing SSCRs in a high enrichment assembly is less than in a low enrichment assembly. This tends to offset the longer SSCR insertion time possible in high enrichment assemblies. On the other hand, the cycle length and the uranium utilization increase with increasing enrichment, although the effect appears to be levelling off even at $3.5 \mathrm{w} / \mathrm{o}$ fuel. This is consistent with PWR experience, but of course there will be increased costs associated with enriching services, which were not considered for this parameter study.

4.1.3. Use of Mixed-Oxide Fuels. In order to assess the impact of our choice to utilize an open fuel cycle with slightly-enriched fuel, two SESSR designs using mixed plutonium-uranium oxide (MOX) fuel were investigated. The results of these parameter studies were presented earlier [2]. The MOX designs used an initial plutonium concentration of $6.0 \mathrm{w} / \mathrm{o}$ total plutonium in fuel heavy metal. The initial plutonium isotopics were typical of those of discharged conventional LWR fuel. We found that while the higher F/M cases for both the conventional uranium and the MOX designs showed higher conversion and fissile inventory ratios, these were achieved at the expense of making the MTC less positive and decreasing the spectral shift advantage.

4.2. Reference SESSR Design. Based on the parameter studies and other analyses summarized above, we have arrived at a new reference design that has a F/M somewhat higher than that of a typical PWR $(\sim 0.54)$, when SSCRs are inserted, and somewhat lower when SSCRs are withdrawn. We present key parameters of our new SESSR design and a summary of our neutronic analyses in the remainder of this section and $\mathrm{T} / \mathrm{H}$ analyses in Section 4.3. Fuel cycle length calculations both for torch and equilibrium core configurations are presented in Section 4.4. Finally, we conclude with a summary of the calculated BOC reactivity parameters, including MTC. 
4.2.1. SESSR Assembly Design. To maximize the spectral shift advantage and maintain adequate $\mathrm{T} / \mathrm{H}$ margins as discussed above, we have selected the SES SR design represented by Case 14 in Table I as our reference design for further studies at the global level. This reference design has a F/M of 0.790 with SSCRs inserted and 0.509 with SSCRs withdrawn, which bracket a typical PWR value of 0.54 . Figure 4 illustrates the reference SESSR assembly configuration that is being examined and Table II contains core parameters for the reference SESSR design as well as parameters for two typical PWR configurations $[10,11]$ that have been used for comparison with the SESSR designs in this report.

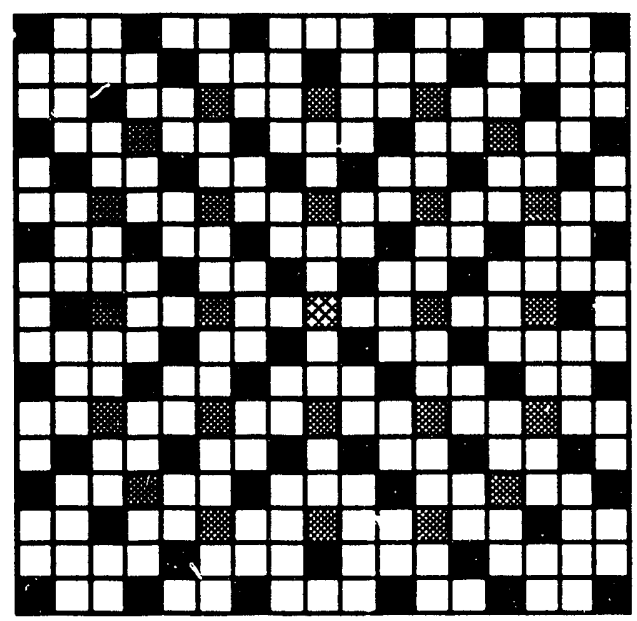

Euel to Moderator Ratio

Spectral Shift Assembly: SSCRs In $\quad 0.790$ SSCRs Out $\quad 0.509$

Control Assembly: $\quad 0.688$

\author{
Fuel Rod \\ Spectral Shift Control Rod (SSCR) \\ Control Rod (CR) or SSCR \\ Instrument Tube
}

Assembly Dimensions (mm)

$\begin{array}{lr}\text { Fuel Radius } & 4.102 \\ \text { Clad Inner Radius } & 4.178 \\ \text { Clad Outer Radius } & 4.750 \\ \text { Pin Cell Pitch } & 11.214 \\ \text { Guide Tube Inner Radius } & 5.175 \\ \text { Guide Tube Outer Radius } & 5.607\end{array}$

Figure 4. 17x17 SESSR Reference Assembly

The revised fuel assembly layout represented by Figure 4 represents a substantial improvement in intra-assembly peaking factor over those obtained earlier [2]. The intraassembly peaking factor, with SSCRs inserted, has been decreased from 1.10 to 1.04 , 
and, with SSCRs withdrawn, from 1.18 to 1.04 . Figure 5 depicts the assembly pin power distributions for three different enrichments for both the SSCR assemrly and the control rod (CR) assembly. This optimized design has also resulted in a slight increase in the batch cycle length and spectral shift advantage as noted in Section 4.4.

\section{Active Core \\ Diameter $(m)$ \\ Height (m) \\ Fuel Assembly \\ Number in core \\ Rod Array \\ Rods/Assembly \\ Rod Pitch (mm, \\ Assembly Pitch (mm) \\ CR/SSCR Tube ID (mm) \\ CR/SSCR Tube OD (mm) \\ Number of SSCR/CR}

Fuel Rods in Core

Enrichment (w/o)

Region 1

Region 2

Region 3

\section{Thermal-Hydraulics}

Core Thermal Power (MWt)

Linear Heat Rate $(\mathrm{kW} / \mathrm{m})$

System Pressure (MPa)

Coolant Flow Rate $(\mathrm{Mg} / \mathrm{s})$

Inlet Temperature $(\mathrm{K})$

Core Temperature Rise (K)

Core Pressure Drop (MPa)
Table II. Selected Core Parameters

$\begin{array}{ccc}\text { SESSR } & \text { Millstone-3 [11] } & \text { Bellefonte [10] } \\ 3.56 & 3.37 & 3.52 \\ 3.63 & 3.66 & 3.63 \\ & & \\ 259 & 193 & 205 \\ 17 \times 17 & 17 \times 17 & 17 \times 17 \\ 200 & 264 & 264 \\ 11.21 & 12.60 & 12.75 \\ 191.7 & 215.0 & 218.1 \\ 10.35 & 11.43 & 10.92 \\ 11.21 & 12.24 & 11.81 \\ 88 & 24 & 24 \\ (64 / 24) & & \\ & & \\ 53800 & 50952 & 54120 \\ & & \\ 2.0 & & \\ 2.5 & 2.4 & 2.96 \\ 3.0 & 2.9 & \text { average }\end{array}$

$\begin{array}{ccc}3618 & 3411 & 3618 \\ 18.0 & 17.8 & 17.9 \\ 15.51 & 15.51 & 15.51 \\ 16.11 & 17.74 & 18.96 \\ 562 & 565 & 573 \\ 41 & 35 & 31 \\ 0.117 & 0.061 & 0.058\end{array}$

All SESSR fuel assemblies are mechanically identical and can be used as either SSC assemblies, in which all 88 control guide tube locations are filled with SSCRs connected to a single spider assembly, or as control assemblies, with 24 control rods connected to a spider assembly and 64 SSCRs not connected. The core consists of 269 assemblies in a 


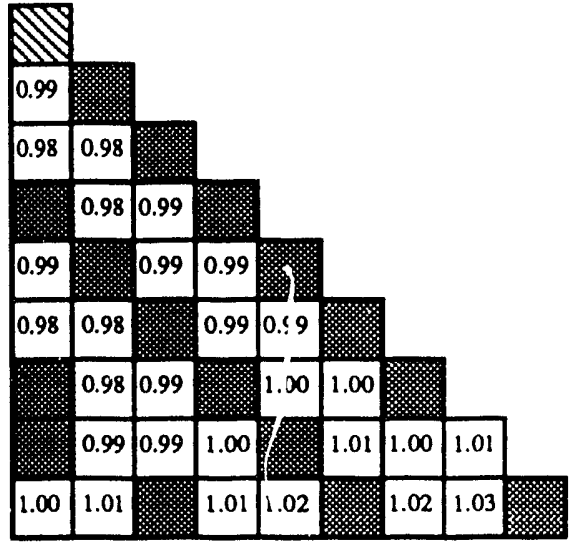

$2.0 \mathrm{w} / \mathrm{o}$ Spectral Shift Assembly (SSCR low)

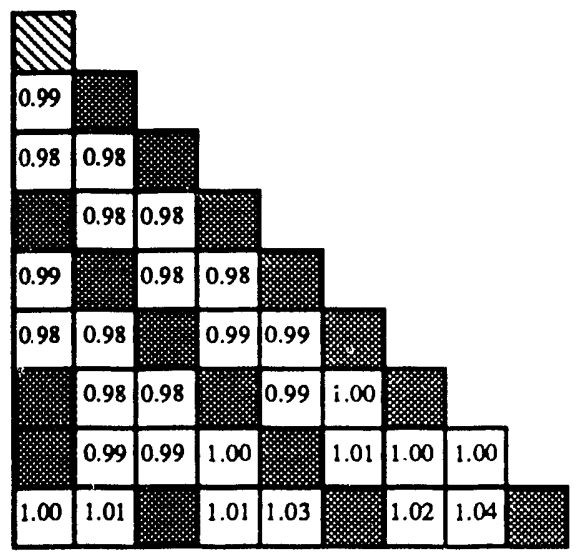

2.5 w/o Spectral Shift Assembly (SSCR medium)

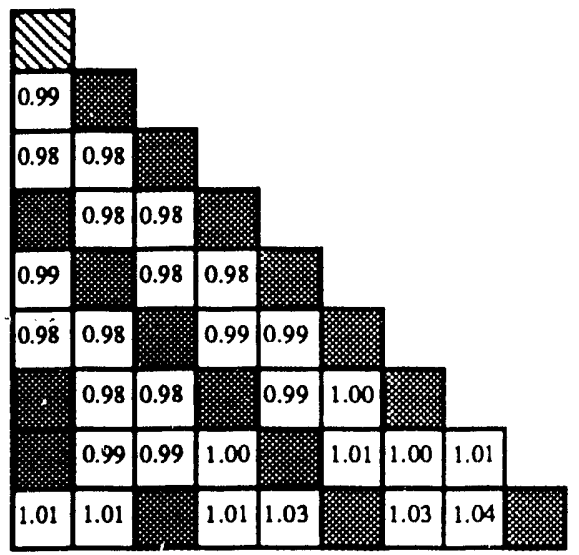

3.0 w/o Spectral Shift Assembly (SSCR high)

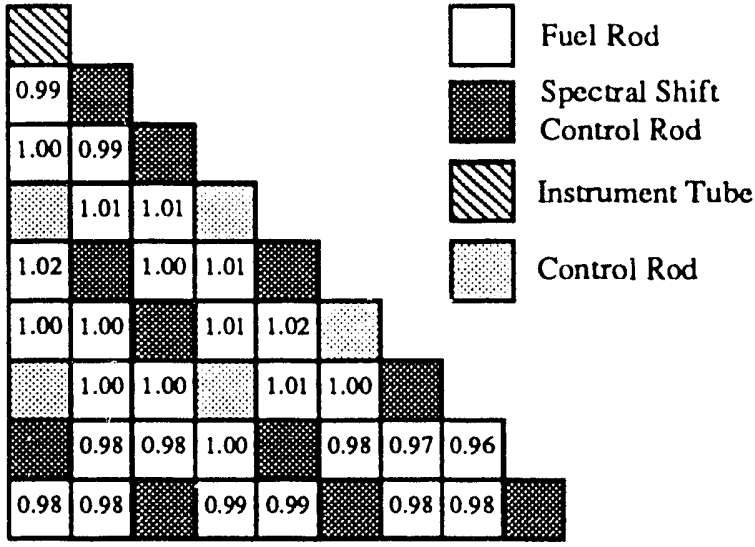

2.0 w/o Control Assembly (CR low)

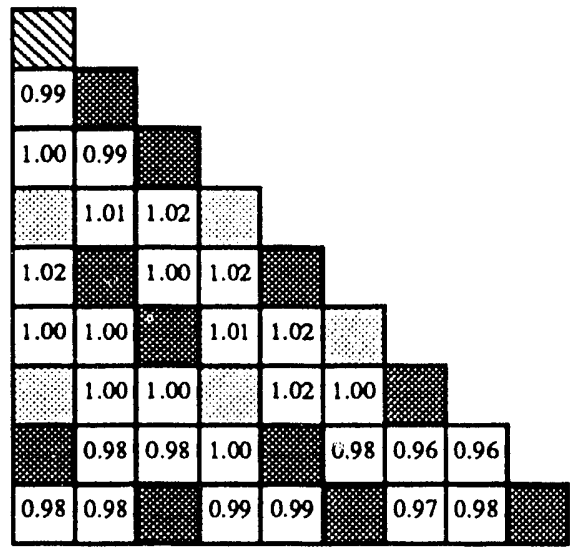

2.5 w/o Control Assembly (CR medium)

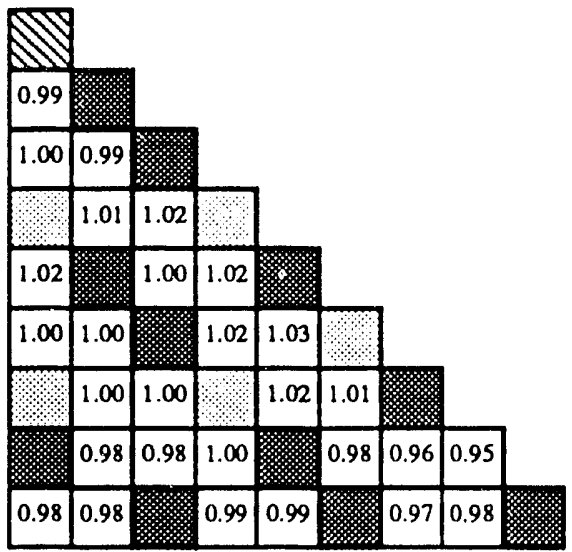

$3.0 \mathrm{w} / \mathrm{o}$ Control Assembly (CR high)

Figure 5. Assembly Pin Power Distributions 
three-enrichment $(2.0,2.5,3.0 \mathrm{w} / \mathrm{o})$ pattern with 57 control assemblies. In Section 4.2.2 below, we summarize the global analyses inciuding the calculation of critical boron concentration, MTC, and control rod worths.

4.2.2. Global SESSR Analyses at BOC. Using the global core layout depicted in Figure 6 , we have carried out $1 / 8$ core multigroup diffusion theory analyses using the UM2DB code with cross sections determined by CPM-2. The UM2DB code is a substan:ially revised version of the $2 \mathrm{DB}$ code [12].

\begin{tabular}{|c|c|c|c|c|c|c|}
\hline $\begin{array}{l}\text { CR } \\
\text { low }\end{array}$ & & & & $\underset{x x X}{X X X}$ & \multicolumn{2}{|c|}{$\begin{array}{l}\text { Assembly type } \\
\text { Enrichment type }\end{array}$} \\
\hline $\begin{array}{l}\text { SSCR } \\
\text { low }\end{array}$ & $\begin{array}{c}\text { SSCR } \\
\text { medilim }\end{array}$ & & & & & \\
\hline $\begin{array}{l}\mathrm{CR} \\
\text { low }\end{array}$ & $\begin{array}{l}\text { SSCR } \\
\text { low }\end{array}$ & $\begin{array}{l}\text { SSCR } \\
\text { low }\end{array}$ & & & & \\
\hline $\begin{array}{l}\text { SSCR } \\
\text { low }\end{array}$ & $\begin{array}{l}\text { SSCR } \\
\text { low }\end{array}$ & $\begin{array}{l}\text { SSCR } \\
\text { low }\end{array}$ & $\begin{array}{l}\text { SSCR } \\
\text { low }\end{array}$ & & & \\
\hline $\begin{array}{l}\text { CR } \\
\text { low }\end{array}$ & $\begin{array}{c}\text { SSCR } \\
\text { medium }\end{array}$ & $\begin{array}{l}\mathrm{CR} \\
\text { low }\end{array}$ & $\begin{array}{c}\text { SSCR } \\
\text { medium }\end{array}$ & $\begin{array}{l}\mathrm{CR} \\
\text { low }\end{array}$ & & \\
\hline $\begin{array}{l}\text { SSCR } \\
\text { medium }\end{array}$ & $\begin{array}{c}\text { SSCR } \\
\text { low }\end{array}$ & $\begin{array}{c}\text { SSCR } \\
\text { medium }\end{array}$ & $\begin{array}{c}\text { SSCR } \\
\text { medium }\end{array}$ & $\begin{array}{c}\text { SSCR } \\
\text { medium }\end{array}$ & $\begin{array}{c}\mathrm{CR} \\
\text { medium }\end{array}$ & \\
\hline $\begin{array}{l}\text { CR } \\
\text { low }\end{array}$ & $\underset{\text { medium }}{\text { SSCR }}$ & $\begin{array}{l}\mathrm{CR} \\
\text { low }\end{array}$ & $\underset{\text { medium }}{\text { SSCR }}$ & $\begin{array}{l}\text { SSCR } \\
\text { low }\end{array}$ & $\begin{array}{l}\text { SSCR } \\
\text { high }\end{array}$ & $\begin{array}{l}\text { SSCR } \\
\text { high }\end{array}$ \\
\hline $\begin{array}{c}\text { SSCR } \\
\text { medium }\end{array}$ & $\begin{array}{l}\text { CR } \\
\text { low }\end{array}$ & $\begin{array}{c}\text { SSCR } \\
\text { medium }\end{array}$ & $\begin{array}{l}\text { SSCR } \\
\text { high }\end{array}$ & $\begin{array}{l}\text { SSCR } \\
\text { high }\end{array}$ & $\begin{array}{l}\text { SSCR } \\
\text { high }\end{array}$ & \\
\hline $\begin{array}{l}\text { CR } \\
\text { high }\end{array}$ & $\begin{array}{l}\text { SSCR } \\
\text { high }\end{array}$ & $\begin{array}{c}\mathrm{CR} \\
\text { high }\end{array}$ & $\begin{array}{l}\text { SSCR } \\
\text { high }\end{array}$ & $\begin{array}{l}\text { SSCR } \\
\text { high }\end{array}$ & & \\
\hline $\begin{array}{l}\text { SSCR } \\
\text { high }\end{array}$ & $\begin{array}{l}\text { SSCR } \\
\text { high }\end{array}$ & $\begin{array}{l}\text { SSCR } \\
\text { high }\end{array}$ & & B & & \\
\hline
\end{tabular}

Figure 6. SESSR Loading Pattern (1/8 Core) 
The BOC power distributions at hot full power (HFP), calculated using the UM2DB code, with (1) SSCRs inserted in all assemblies and (2) with SSCRs withdrawn in eight assemblies, are illustrated in Figure 7. The relative core power distributions are calculated with a (5x6) homogeneous mesh per assembly. BOC calculations using the UM2DB code yield a critical soluble boron concentration of $1790 \mathrm{ppm}$ at HFP and $1950 \mathrm{ppm}$ at hot zero power (HZP). The calculated values of boron worth and MTC at HZP are $-7.4 \mathrm{pcm} / \mathrm{ppm}$ (1 $\left.\mathrm{pcm}=10^{-5} \Delta k / k\right)$ and $-3.5 \mathrm{pcm} /{ }^{\circ} \mathrm{F}$, respectively.

\begin{tabular}{|c|c|c|c|c|c|c|c|}
\hline $\begin{array}{l}1.06 \\
1.14\end{array}$ & & & $\begin{array}{l}\text { x.xx } \\
\text { y.yy }\end{array}$ & \multicolumn{4}{|c|}{$\begin{array}{l}\text { Relative power map with SSCRs withdrawn } \\
\text { Relative power map with SSCRs inserted }\end{array}$} \\
\hline $\begin{array}{l}0.99 \\
1.06\end{array}$ & $\begin{array}{l}1.11 \\
1.19\end{array}$ & & & & & & \\
\hline $\begin{array}{l}1.07 \\
1.15\end{array}$ & $\begin{array}{l}1.00 \\
1.67\end{array}$ & $\begin{array}{l}1.02 \\
1.08\end{array}$ & & & & & \\
\hline $\begin{array}{l}1.04 \\
1.11\end{array}$ & $\begin{array}{l}1.04 \\
1.10\end{array}$ & $\begin{array}{l}1.07 \\
1.12\end{array}$ & $\begin{array}{l}1.12 \\
1.15\end{array}$ & & & & \\
\hline $\begin{array}{l}1.18 \\
1.24\end{array}$ & $\begin{array}{l}1.25 \\
1.31\end{array}$ & $\begin{array}{l}1.22 \\
1.26\end{array}$ & $\begin{array}{l}1.31 \\
1.32\end{array}$ & $\begin{array}{l}1.25 \\
1.23\end{array}$ & & & \\
\hline $\begin{array}{l}1.28 \\
1.33\end{array}$ & $\begin{array}{l}1.13 \\
1.17\end{array}$ & $\begin{array}{l}1.30 \\
1.32\end{array}$ & $\begin{array}{l}1.29 \\
1.27\end{array}$ & $\begin{array}{l}1.26 \\
1.19\end{array}$ & $\begin{array}{l}1.15 \\
1.08\end{array}$ & & \\
\hline $\begin{array}{l}1.17 \\
1.21\end{array}$ & $\begin{array}{l}1.23 \\
1.27\end{array}$ & $\begin{array}{l}1.16 \\
1.17\end{array}$ & $\begin{array}{l}1.19 \\
1.14\end{array}$ & $\begin{array}{l}1.35^{*} \\
0.87\end{array}$ & $\begin{array}{l}0.86 \\
0.80\end{array}$ & $\begin{array}{l}0.51 \\
0.48\end{array}$ & \\
\hline $\begin{array}{l}1.11 \\
1.16\end{array}$ & $\begin{array}{l}1.04 \\
1.07\end{array}$ & $\begin{array}{l}1.04 \\
1.05\end{array}$ & $\begin{array}{l}1.00 \\
0.99\end{array}$ & $\begin{array}{l}0.79 \\
0.75\end{array}$ & $\begin{array}{l}0.49 \\
0.46\end{array}$ & & \\
\hline $\begin{array}{l}1.01 \\
1.05\end{array}$ & $\begin{array}{l}0.91 \\
0.94\end{array}$ & $\begin{array}{l}0.85 \\
0.87\end{array}$ & $\begin{array}{l}0.61 \\
0.61\end{array}$ & $\begin{array}{l}0.40 \\
0.39\end{array}$ & & & \\
\hline $\begin{array}{l}0.51 \\
0.53\end{array}$ & $\begin{array}{l}0.47 \\
0.49\end{array}$ & $\begin{array}{l}0.37 \\
0.38\end{array}$ & & am & & & \\
\hline
\end{tabular}

Figure 7. SESSR BOC Hot Full Power Relative Core Power Map (*Indicates SSCR Withdrawn from Assembly) 
Control rod worth calculations were performed for our reference SESSR design to ensure that a sufficient shutdown margin exists in the design, while the number of $\mathrm{CR}$ assemblies, containing fewer SSCRs than SSCR assemblies, is minimized. We define shutdown margin here as the amount by which the reactor would be subcritical at HZP if all rod cluster control assemblies were tripped, but with the assumption that the highest worth assembly remains fully withdrawn and no change in boron or :non concentration takes place. Reference [12], the Final Safety Analysis Report (FSAF) for the Millstone Nuclear Power Station Unit 3 (MNP-3), shows a total control rod wortı of $8.95 \% \Delta k / k$ at HZP and a shutdown margin of $4.33 \% \Delta k / k$ at the beginning of the first cycle. Our final SESSR control assembly design and global core loading pattern have been chosen so as to match the total MNP-3 control rod worth, without explicit representation of the stuck-rod condition.

To establish confidence in the accuracy of the CPM-2 and UM2DB codes for rod worth calculation, we used the codes to simulate insertion of all control rods into critical core configurations for the MNP-3 reactor. Our calculated rod worths of $9.21 \% \Delta k / k$ and 9.68\% $\Delta k / k$ for HZP and HFP, respectively, compare favorably with the FSAR value of $8.95 \% \Delta k / k$ for HZP. 'The absorber material was represented as Ag-In-Cd in our CPM-2 calculation, whereas it is unclear if $\mathrm{Ag}-\mathrm{In}-\mathrm{Cd}$ or $\mathrm{Hf}$ was used in the FSAR calculation. Given this uncertainty regarding the absorber material, the accuracy of the CPM-2 and UM2DB codes in calculating the control rod worth can be considered quite acceptable; the relative error between the FSAR control rod worth and our calculation for HZP is iess than $3 \%$.

Using Ag-In-Cd as the control absorber material, we used the CPM-2 and UM2DB codes to calculate a HFP control rod worth of $9.26 \% \Delta \mathrm{k} / \mathrm{k}$ for the SESSR. This calculation was done for the global loading pattern shown in Figure 6, with all full-length control assemblies and SSCRs inserted. Although the SESSR rod worth is somewhat smaller than 
our calculation of $9.68 \% \Delta k / k$ for the MNP-3 reactor, we expect that our shutdown margin will be sufficiently larger than the typical minimum value of $1.6 \% \Delta k / k$ [11]. It should be noted that the SESSR core consists of a total of 269 assemblies, including 57 control assemblies, compared with a total of 193 assemblies, including 61 control assemblies, for the MNP-3 reactor.

The requirement of fewer control assemblies in the SESSR core can be explained by examining, at the assembly level, the fractional change $\Delta \Sigma_{a 2} / \Sigma_{a 2}$ in the thermal absorption cross section due to the control absorbers. The parameter $\Delta \Sigma_{a 2} / \Sigma_{a 2}$ is approximately proportional to the ratio $N_{c r} / N_{f}$ where $N_{c r}$ is the number of control rods and $N_{f}$ is the number of fuel rods in an assembly. Since the ratio $N_{c r} / N_{f}$ is 0.12 for the SESSR assembly, compared with 0.091 for the MNP-3 assembly, the parameter $\Delta \Sigma_{a 2} / \Sigma_{a 2}$ is larger in an SESSR assembly than in an MNP-3 assembly. With the reactivity worth $\Delta k / k$ of control absorbers approximately proportional to $\Delta \Sigma_{a 2} / \Sigma_{a 2}$, we expect that, even with fewer control assemblies, the total control rod worth of the SESSR core will be nearly equal to that of the MNP-3 reactor.

4.3. Thermal-hydraulic Analysis. A preliminary $\mathrm{T} / \mathrm{H}$ analysis of the SESSR core has been performed with the MITH code [13] for our reference design featuring 269 fuel assemblies. Our SESSR design is based on the Bellefonte plant [10], but uses a semi-tight lattice arrangement for spectral shifting. We present $\mathrm{T} / \mathrm{H}$ parameters obtained for the SESSR design, with a few parametric combinations of core power output and flowrate. We also compare the results with those for the MNP-3 [11] and Bellefonte plants.

The MITH code performs steady-state, closed-channel T/H analysis for light water reactor coolant channels. The original version of MITH calculates critical heat flux using the W-3 correlation developed by Westinghouse Electric Corporation [14]. However, the tight pitch of the SESSR results in a hydraulic diameter which falls below the range allowed in the W-3 correlation. Therefore, another correlation [15], produced by Babcock 
and Wilcox and Virginia Polytechnic Institute and State University for tight lattices, was incorpo:ated into MITH for the present study. The code allows representation of subcooled liquid flow, and subcooled and saturated two-phase 7ow. Although the code can represent a hot channel as well as a core-average channel, cross flow between channels is not modeled. The hydraulic model calculates frictional, gravitational, and accelerational pressure drops in a coolant channel. Pressure loss terms associated with spacer grids, and inlet and outlet plena may also be represented in MITH, but have been ignored in our analysis, for lack of specific information. After the average-channel calculation is done, MITH uses an input value of the enthalpy-rise hot channel factor $F_{\Delta h}$ to calculate the hotchannel heat flux and iterates on the hot-channel flowrate so that the pressure drop across the hot channel matches the average-channel pressure drop.

Following standard practice [10.16] we: assume a bypass flow fraction $f_{b y}$ to represent the coolant flow associated with the baffle region, instrumentation thimble and control rod positions. Given the total vessel flowrate $W_{\mathrm{v}}$ and $f_{b y}$, we obtain the core flowrate $W_{c}$ :

$$
W_{c}=\left(1-f_{b y}\right) W_{\mathrm{v}}
$$

To account for the coolant flow bypassing fuel rods, we assume a uniform distribution of flow over the lattice flow area $A_{L}$ and the non-lattice flow area $A_{N L}$ of the core, and calculate the lattice flowrate $W_{L}$ as the fraction of the total core flowrate $W_{c}$ associated with the lattice flow area. Thus, defining the lattice fraction $f_{L}$ of core flow area as:

$$
f_{L}=A_{L} /\left(A_{L}+A_{N L}\right)
$$

we obtain the lattice flowrate $W_{L}$ :

$$
W_{L}=f_{L} W_{C}
$$

The non-lattice flow area $A_{N L}$ should include burnable absorber positions in standard PWR designs and SSCR positions in the SESSR design. With the lattice flowrate $W_{L}$ calculated through Eq. (3), we properly represent, in a closed-channel model, the mass velocity $G$ of 
cnolant flow through the core. Finally, to satisfy the energy balance across the core, we determine the lattice power output $Q_{L}$ as:

$$
Q_{L}=f_{L} Q_{c}
$$

where $Q_{c}$ is the total core power output. Using Eqs. (3) and (4), we may obtain the coreaverage enthalpy rise $\Delta h_{c}$ as:

$$
\Delta h_{C}=Q_{c} / W_{C}=Q_{L} / W_{L} .
$$

The MITH code divides both $W_{L}$ and $Q_{L}$ by the total number of fuel rods in the core and performs a single-channel $\mathrm{T} / \mathrm{H}$ analysis representing individual coolant channels.

In selecting $\mathrm{T} / \mathrm{H}$ parameters for our SESSR design presented in Table III, we have considered the following constraints:

(1) The total number of fuel rods for the core should be nearly equal to or greater than that of the Bellefonte design so that the core-average linear heat generation rate and surface heat flux will be comparable to the corresponding Bellefonte values.

(2) In anticipation of the need to reduce the core flowrate so that the pressure drop across the tight-lattice core is minimized, the inlet coolant temperature is reduced from the Bellefonte design. A core-average coolant temperature of $590^{\circ} \mathrm{F}$ is chosen to approximate the MNP-3 design value of 588.8 F.

(3) The hot-channel exit quality for the SESSR design calculated with the MITH code should not exceed the corresponding value similarly calculated for the Bellefonte design. As noted in Table III, the MITH calculation yields a positive exit quality in the Bellefonte hot channel, perhaps indicating a limitation of the simple closed-channel formulation of the code.

To establish some confidence in the accuracy of the MITH single-channel model, we have simulated rated conditions of the Bellefonte and MNP-3 plants. Table III compares the MITH results and design data available in the MNP-3 FSAR [11] and the Standard Safety Analysis Report (SSAR) for the Bellefonte core [10]. We note an 


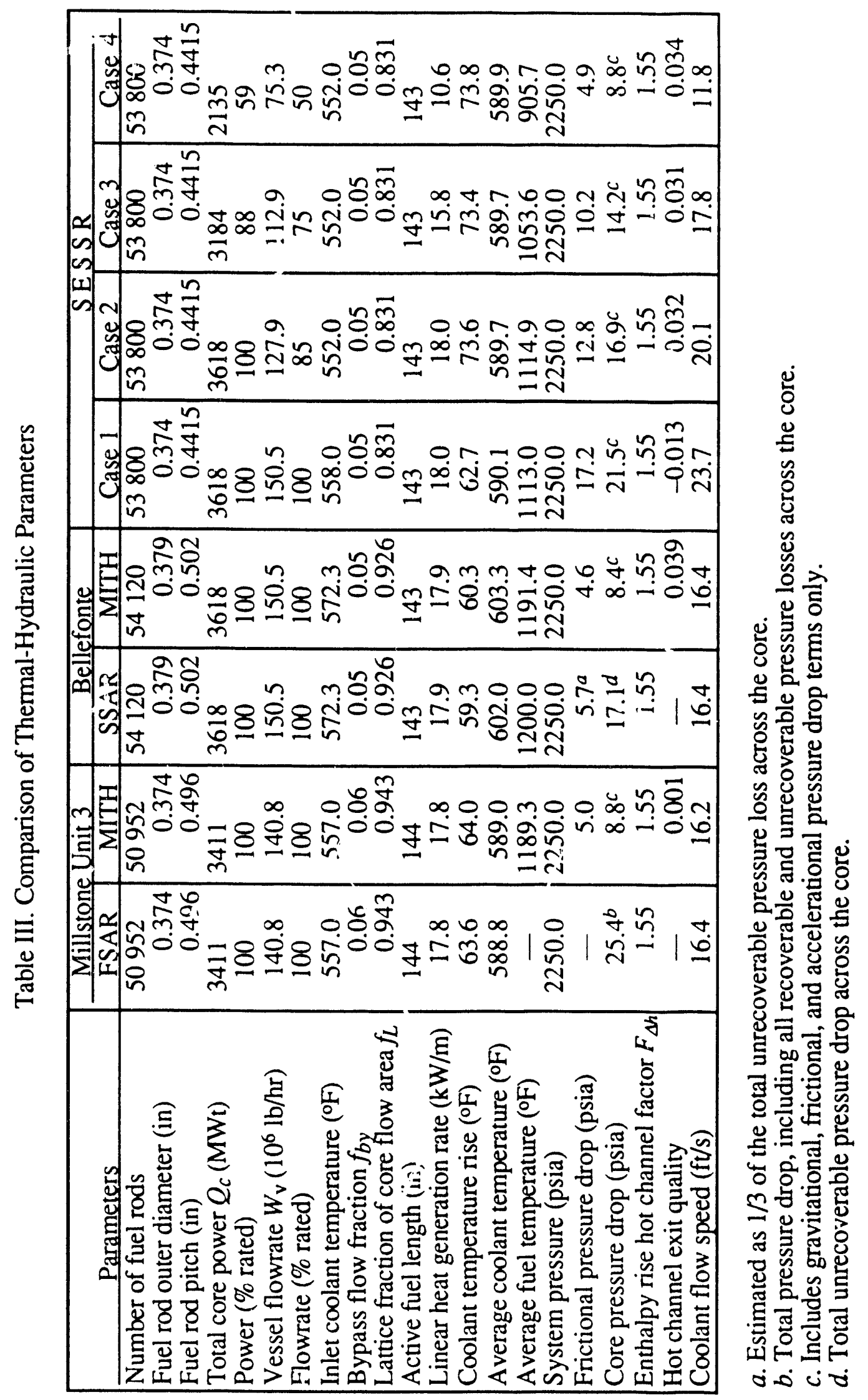


excellent agreement for the average coolant temperature rise across the core, average coolant temperature, averagc fuel temperature, and coolant how speed. Due to lack of detailed data in the FSAR or SSAR, however, the pressure drop comparison is limited to the frictional pressure drop fo: the Bellefonte design. Based on an estimate [16] that the frictional pressure drop accounts for $33 \%$ of the total unrecoverable pressure drop in a $3800 \mathrm{MWt}$ B\&W plant, a value of 5.7 psia is obtained for the Bellefonte frictional pressure drop, which shows only a marginal agreement with the MITH value of 4.6 psia.

For the SESSR design, we present four parametric cases showing different combinations of core power output and flowrate. Case 1 uses rated power and flow of the Bellefonte design, yielding a core temperature rise comparable to the Bellefonte design and a favorable thermal margin in the hot channel. The pressure drop and coolant flow speed are, however, drastically increased due to the reduced flow area of the SESSR design. Case 2 , based on rated power but $85 \%$ of rated flow, shows improvements in the pressure drop and flow speed at the price of an increased temperature rise and boiling in the hot channel. The exit quality of 0.032 in the hot channel is still less than the Bellefonte value of 0.039 calculated with the MITH code. The total pressure drop of 16.9 psia across the core for Case 2 is about twice as large as the MITH value of 8.4 psia for Bellefonte. Cases 3 and 4 show that a further reduction in the pressure drop requires decreases in both power and flowrate.

Although SESSR Case 2 still shows considerable increases both in the pressure drop and coolant flow speed from the corresponding Bellefonte results, we consider this case as our reference SESSR design. Since the total unrecoverable pressure drop across the reactor vessel is estimated [16] to be 50 psia, together with a pump head of $90 \sim 100$ psia, for Bellefonte, an effort could be made to minimize unrecoverable pressure losses associated with spacer grids, and inlet and outlet plena. We present various design 
parameters for our reference SESSR design in Table IV. Key data from Tables III and IV are also summarized in Table II.

Table IV. Design Parameters for the SESSR

Active Core

Diameter ( $\mathrm{ft}$ )

Height (ft)

11.92

Fuel Assembly

Number in core $\quad 269$

Rod array $\quad 17 \times 17$

Rod pitch (in) $\quad 0.4415$

Assembly pitch (in) $\quad 7.545$

Assembly gap (in) $\quad 0.040$

Number of Rods in Core

Fuel rod $\quad 53800$

Spectral shift control rod $\quad 22304$

Control rod 1368

Instrument tube $\quad 269$

Number of Rods in Spectral Shift Control Rod (SSCR) Assembly

Fuel rod

Spectral shift control rod $\quad 88$

Instrument tube

Number of Rods in Control Rod (CR) Assembly

$\begin{array}{lr}\text { Fuel rod } & 200 \\ \text { Spectral shift control rod } & 64 \\ \text { Control rod } & 24 \\ \text { Instrument tube } & 1\end{array}$

Fuel Rod

Pellet radius (in)

Clad inner radius (in)

0.1615

Clad outer radius (in)

0.1645

0.187

Instrument Tube/Spectral ShifuControl Rod

Inner radius (in)

0.20375

Outer radius (in)

0.22075 
4.4. Fuel Cycle Calculations. We present in this section a brief review of the simplified fuel cycling method of the CYCLE code [2] both for batch and equilibrium core configurations. A summary of the results of fuel cycle length calculations for our reference design is also presented.

To explain the basic neutronic advantages of our SSC concept and illustrate the CYCLE method, we show in Figure 8 the burnup-dependent reactivity and principal fissile nuclide inventory for the $2.5 \mathrm{w} / \mathrm{o}$ SESSR assembly represented by Case 5 in Table I. The curves representing SSCRs withdrawn at BOC, with a F/M of 0.54 , closely approximate a conventional PWR assembly of the same enrichment (with no burnable poison rods). The difference $\Delta \mathrm{k}$ between the $\mathrm{k}_{\infty}$ curves in Figure 8, with SSCRs inserted and withdrawn at various burnups, is an approximate measure of the SSC advantage over a typical PWR. With SSCRs inserted, the ${ }^{235} \mathrm{U}$ clepletion rate is slightly decreased and the ${ }^{239} \mathrm{Pu}$ production rate is substantially increased due to the hardened spectrum. This results in an increased cycle length compared to a conventional PWR by $15-25 \%$.

The CYCLE code was developed to estimate the SESSR cycle length frc: $1 k_{\infty}$ curves such as those illustrated in Figure 8. The CYCLE code applics a fraction of the burnupdependent SSC $\Delta k$ as needed to maintain $k_{\infty}$ above a given cutoif poin $t$, which was chosen as 1.020 for all of the work described here. This approximates the reactivity behavior of a reactor, where the SSCRs are withdrawn from only a few assernblies at a given time. A detailed description of the CYCLE code is included as Appendix A to Ref. [2].

One of the most important observations is the interesting tradeoff between the objective to harden the spectrum through SSCR insertion and the need to maintain criticality through SSCR withdrawal. The SSCRs represent a source of positive reactivity and are withdrawn to balance the negative reactivity due to fuel depletion. On the other hand, production of fissile plutonium is maximized with the SSCRs inserted, therefore the longer one can refrair from withdrawing the SSCRs, the greater the cycle length for a given 
core/SSCR configuration. The need to maintain a critical reactor may, however, force the withdrawal of SSCRs early in the cycle offsetting some of the potential advantages of the SESSR.
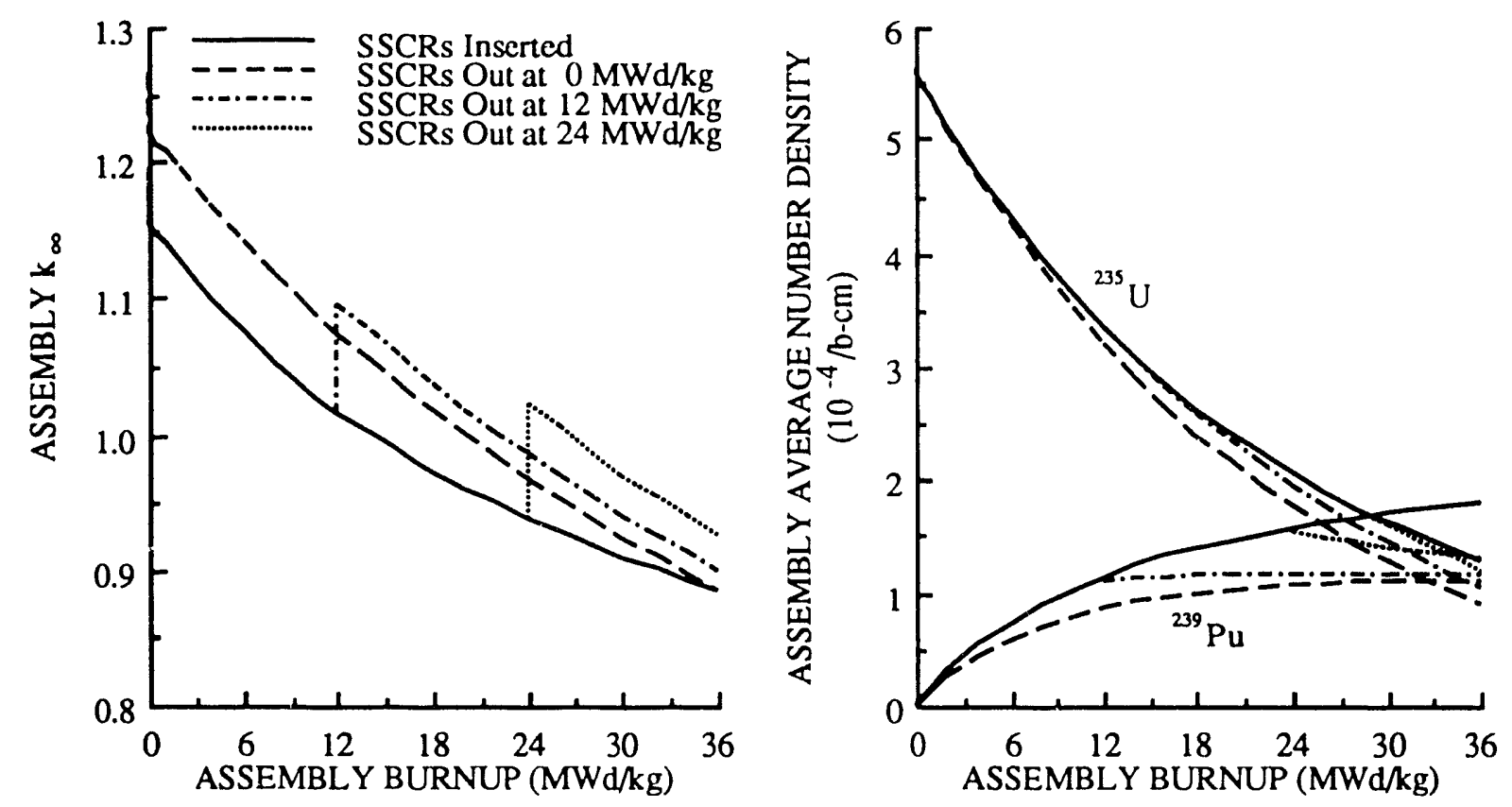

Figure 8. Assembly $\mathrm{k}_{\infty}$ and Fissile Nuclide Inventory vs. Assembly Burnup ( $\left.2.5 \mathrm{w} / \mathrm{o}\right)$

In addition to batch core fuel analyses, equilibrium core analyses have been performed with the CYCLE code for several configurations. The equilibrium cycle methodology is based on the assumption of equal power sharing among the three enrichment zones, and a linear dependence of SSC $\Delta k$ between actual SSCR withdrawal times. Reinsertion of SSCRs is also allowed with this method, which complicates the $\Delta \mathrm{k}$ interpolation procedure because the linear interpolation must account for previous SSCR residence time as well as the time for SSCR withdrawal in the current cycle. In our simple cycling study, an effective value of the cumulative SSCR residence time is used to represent SSCR reinsertion effects. 
Batch cycle length calculations for our reference design are summarized in Tauie V for two different fuel enrichments. The percentage increase in cycle length for each case versus a typical PWR assembly [11] is also tabulated. Finally, the energy extracted per kg of uranium mined is also tabulated to show the effect of the spectral shift designs on uranium utilization.

Table V. Batch Core Cycle Length

(Pin Cell Piich $=11.21 \mathrm{~mm}, 88$ SSCRs, F/M $=0.790-0.509$ )

\begin{tabular}{|c|c|c|c|c|c|}
\hline & \multicolumn{3}{|c|}{ Cycle Length (MWd/kg U) } & & \\
\hline $\begin{array}{l}\text { Enrichment } \\
\left(w / o^{235} U\right)\end{array}$ & $\begin{array}{c}\text { Reference } \\
\text { PWR }\end{array}$ & SESSR & $\begin{array}{c}\text { SESSR } \\
\text { SSCRS Out }\end{array}$ & $\begin{array}{l}\text { \% Increase } \\
\text { Due to } \\
\text { Spectral } \\
\text { Shift }\end{array}$ & $\begin{array}{c}\text { \% Increase } \\
\text { Relative to } \\
\text { Reference } \\
\text { PWR }\end{array}$ \\
\hline 2.5 & 17.8 & 22.3 & 18.6 & 19.9 & 25.3 \\
\hline 3.0 & 22.7 & 27.9 & 23.4 & 19.2 & 22.9 \\
\hline
\end{tabular}

\begin{tabular}{|c|c|c|c|c|c|}
\cline { 2 - 6 } \multicolumn{1}{c|}{} & \multicolumn{3}{c|}{ Fuel Utilization (MWd/kg U mined) } & \multicolumn{1}{c|}{} \\
\hline $\begin{array}{l}\text { Enrichment } \\
\left(\mathrm{w} / \mathrm{o}^{235} \mathrm{U}\right)\end{array}$ & $\begin{array}{c}\text { Reference } \\
\text { PWR }\end{array}$ & SESSR & $\begin{array}{c}\text { SESSR } \\
\text { SSCRs Out }\end{array}$ & $\begin{array}{c}\text { Increase } \\
\text { Due to } \\
\text { Spectral } \\
\text { Shift }\end{array}$ & $\begin{array}{c}\text { \% Increase } \\
\text { Relative to } \\
3.0 \text { w/o } \\
\text { PWR }\end{array}$ \\
\hline 2.5 & 3.87 & 4.85 & 4.04 & 20.0 & 19.8 \\
\hline 3.0 & $4.05^{*}$ & 4.98 & 4.17 & 19.4 & 23.0 \\
\hline
\end{tabular}

Table VI presents equilibrium core cycle lengths calculated for our reference SESSR design. The relative spectral shift advantage of $17 \%$ for the equilibrium cycles is somewhat less than 19 20\% for the batch cycles. The ratio of the discharge burnup of the equilibrium cycle to that of the batch cycle is approximately equal to the theoretical value of $2 n /(n+1)=$ 1.5 with three enrichment zones $(n=3)$, for both feed enrichments and with or without spectral shifting, as shown in Table VI.

Based on the batch and equilibrium core comparisons contained in Tables V and VI, and other parametric studies reported earlier $[2,3]$, we note that cycle lengths are typically increased by 15 to $30 \%$, relative to the reference PWR, through the use of spectral shift 
Table VI. Equilibrium Core Cycle Length

(Pin Cell Pitch $=11.21 \mathrm{~mm}, 88$ SSCRs, F/M $=0.790-0.509$ )

\begin{tabular}{|c|c|c|c|c|c|}
\hline \multirow[b]{2}{*}{$\begin{array}{l}\text { Enrichment } \\
\left(w / 0^{235} U\right)\end{array}$} & \multicolumn{2}{|c|}{$\begin{array}{c}\text { Equilibrium Cycle } \\
\text { Discharge Bumup } \\
\text { (MWd/kg U) }\end{array}$} & \multicolumn{2}{|c|}{$\begin{array}{c}\text { Ratio of Equilibrium } \\
\text { Discharge Burnup to } \\
\text { Batch Burnup }\end{array}$} & \multirow{2}{*}{$\begin{array}{c}\% \\
\text { Increase } \\
\text { Due to } \\
\text { Spectra } \\
\text { Shift }\end{array}$} \\
\hline & SESSR & $\begin{array}{c}\text { SESSR } \\
\text { SSCRs } \\
\text { Out }\end{array}$ & SESSR & $\begin{array}{c}\text { SESSR } \\
\text { SSCRs } \\
\text { Out } \\
\end{array}$ & \\
\hline 2.5 & 33.4 & 28.5 & 1.50 & 1.53 & 17.2 \\
\hline 3.0 & 42.2 & 36.2 & 1.51 & 1.55 & 16.6 \\
\hline
\end{tabular}

control for a wide range of enrichments (1.5 3.5 w/o). The spectral shift advantage is fairly insensitive to enrichment, as noted in Section 4.1.2.

Table VII presents estimates of the equilibrium cycle fuel costs and integrated conversion ratios for our reference SESSR for two different fuel enrichments. Values for a typical PWR assembly [11] are also shown for comparison. The fuel costs are estimated and include only the costs of $\mathrm{U}_{3} \mathrm{O}_{8}, \mathrm{U}_{3} \mathrm{O}_{8}-\mathrm{UF}_{6}$ conversion, enrichment and fuel fabrication. The costs for these materials and services and the interest rate are based on 1987 fuel cost information [17]. The cost calculation assumed a "once through" fuel cycle with no reprocessing and no credit taken for residual uranium or plutonium. In accordance with recommendations in Reference 17 a one mill/kWh charge for the ultimate disposal of the spent fuel has seen included.

The conversion ratios presented are integrated conversion ratios over the life of the fuel assemblies. The CPM-2 code was modified slightly to perform this calculation. The conversion ratios presented are the quotients of the integrated neutron captures in the fertile nuclides ${ }^{238} \mathrm{U}$ and ${ }^{240} \mathrm{Pu}$ divided by the integrated neutron absorptions in the fissile nuclides ${ }^{235} \mathrm{U},{ }^{239} \mathrm{Pu}$ and ${ }^{241} \mathrm{Pu}$. The calculations for the SESSR were performed for a representative three-cycle fuel assembly lifetime in which SSCRs are inserted at the beginning of each cycle and then withdrawn later in the cycle. As can be seen from the data in Table VII, the SESSR shows a fuel cost advantage of approximately $12 \%$ and a 
conversion ratio approximately $10 \%$ higher than the referenze PWR. Again, this adyantage is not very sensitive to the initial fuel enrichment.

Table VII. Estimated Fuel Costs and Conversion Ratios

(Pin Cell Pitch $=11.21 \mathrm{~mm}, 88$ SSCRs, F/M $=0.790-0.509$ )

\begin{tabular}{|c|c|c|c|c|c|c|}
\cline { 2 - 7 } \multicolumn{1}{c|}{} & \multicolumn{3}{c|}{$\begin{array}{c}\text { Fucl Cost } \\
\text { (mills/kWh) }\end{array}$} & \multicolumn{3}{c|}{ Conversion Ratio } \\
\hline $\begin{array}{c}\text { Enrichment } \\
(w / 0235 U)\end{array}$ & $\begin{array}{c}\text { Reference } \\
\text { PWR }\end{array}$ & SESSR & $\begin{array}{c}\text { SESSR } \\
\text { SSCRs Out }\end{array}$ & $\begin{array}{c}\text { Reference } \\
\text { PWR }\end{array}$ & SESSR & $\begin{array}{c}\text { SESSR } \\
\text { SSCRs Out }\end{array}$ \\
\hline 2.5 & 6.08 & 5.33 & 5.93 & 0.65 & 0.71 & 0.63 \\
\hline 3.0 & 6.05 & 5.37 & 5.93 & 0.63 & 0.70 & 0.61 \\
\hline
\end{tabular}

All of the earlier CPM-2 depletion cases used in the earlier reports [2-3] for cycle length estimates were calculated at a zero soluble boron concentration. Realistically, SESSR assemblies would be depleted with a boron letdown curve, having a high boron concentration at BOC which would gradually decrease to zero or a small value at the time at which SSCRs are withdrawn. This can have a substantial effect on the cycle length due to the spectrum effects of the boron, which can be difficult to predict. This was discussed in [3] and we have since made substantial progress towards understanding this phenomenon by developing a macroscopic depletion capability for the SESSR that includes both the effect of soluble boron as well as the SSCR movement. This will be discussed in Section 4.6 below.

4.5. BOC Reactivity Parameters. As discussed in Section 4.1.2, the spectral shift advantage is not particularly sensitive to enrichment changes over a wide range of possible fuel enrichments. The fuel enrichments are thus chosen for our reference SESSR design based on the fuel cycle lengths desired, subject to the constraint that reactivity parameters, e.g., MTC and critical boron concentration, remain acceptable. These practices and constraints are similar to those followed in conventional PWR designs. These constraints are also consistent with our key objective that the proven safety characteristics of conventional PWRs be retained in our SESSR designs. 
Table VIII summarizes the HFP assembly $k_{\infty}$, HZP critical boron concentrations, and HZP MTCs for the reference SESSR assembly design, all at BOC. One SESSR assembly design with burnable poison loaded into the SSCRs was analyzed and the results are included in Table VIII (designated as shimmed SSCRs). The poison roading was chosen to allow it to burn out by EOC and the esultant cycle length was essentially unchanged from the design without burnable poison. Ihess, the initial cycle for the SESSR could include poisoned SSCRs to reduce BOC reactivity while maintaining a negative MTC with negligible effect on cycle length. An additional assembly design with thin fuel rods was also analyzed. The number of SSCRs and the pitch were chosen to yield a F/M range comparable to Case 5 in Table I. The effect was a decrease in cycle length, and there does not appear to be a neutronic advantage for this particular design. The $\mathrm{T} / \mathrm{H}$ characteristics of this design are also changed.

We note that, at the fuel assembly level, unacceptably high critical boron concentrations and positive MTCs are calculated for all three enrichments $(2.0,2.5,3.0$ w/o) of a representative SESSR design (Case 1 in Table VIII, Case 11 in Table I). When neutron leakage is duly accounted for in global multigroup diffusion theory calculations, we obtain a reasonable critical boron concentration of $1820 \mathrm{ppm}$ and an MTC of -0.3 $\mathrm{pcm} / \mathrm{K}$, both at HZP, for this particular design. Our final SESSR design, as presented in Section 4.2.2, is $\mathrm{d}$ 'fferent from the cases tabulated in Table VIII, but has given due considerations for these two reactivity parameters.

4.6. Global Depletion Analysis of the SESSR. The global depletion analysis of the SESSR represents a complex problem. Not only must the effects of core average power, local assembly power, thermal-hydraulic feedback and the time dependent critical boron concentration be taken into consideration as in a conventional PWR, but the effects of spectral shift rod insertion must also be included. These spectral shift effects must not only 
Table VIII. BOC Reactivity Parameters

Case 1: Pin Cell Pitch $=11.42 \mathrm{~mm}$, Fuel Rod Diameter $=9.50 \mathrm{~mm}$, Unshimmed SSCRs

Case 2: Pin Cell Pitch $=11.20 \mathrm{~mm}$, Fuel Rod Diameter $=9.50 \mathrm{~mm}$, Shimmed SSCRs

Case 3: Pin Cell Pitch $=8.36 \mathrm{~mm}$, Fuel Rod Diameter $=7.24 \mathrm{~mm}$, Unshimmed SSCRs

\begin{tabular}{|c|c|c|c|c|}
\hline Case & $\begin{array}{c}\text { Enrichment } \\
\left(\mathrm{w} / \mathrm{o}^{235} \mathrm{U}\right)\end{array}$ & $\begin{array}{c}\text { No Boron } \\
\text { HFP-BOC } \\
\text { k }_{\infty} \\
(\text { SSCRs In) }\end{array}$ & $\begin{array}{c}\text { HZP-BOC } \\
\text { Critical Boron } \\
\text { Concentration } \\
(\mathrm{ppm})\end{array}$ & $\begin{array}{c}\text { HZP-BOC } \\
\text { MTC } \\
(\mathrm{pcm} / \mathrm{K})\end{array}$ \\
\hline \multirow{3}{*}{1} & 1.5 & 1.0912 & 920 & -3.6 \\
\cline { 2 - 5 } & 2.0 & 1.1689 & 1770 & +4.5 \\
\cline { 2 - 5 } & 2.5 & 1.2216 & 2700 & +10.5 \\
\cline { 2 - 5 } & 3.0 & 1.2599 & 3580 & +14.6 \\
\hline 2 & 3.5 & 1.2891 & 4380 & +17.4 \\
\hline 3 & 3.5 & 1.0932 & 2160 & -9.1 \\
\hline
\end{tabular}

include the status of the SSCRs (inserted or withdrawn) they must also consider the SSCR insertion history. This history must take into account both the burnup accumulated with SSCRs inserted and the burnup accumulated since SSCR withdrawal. It was also a goal of the project to perform this analysis without making major modifications to the computer codes being used by the project.

As noted in our previous report [3], an error was discovered in the CPM-2 code shortly before the issuance of that report. Subsequent investigation into the error in the final months of the project revealed that a single line within the code was misplaced, resulting in erroneous calculation of the weight percents of certain fuel assembly compositions for cases in which the soluble poison concentration has changed since the previous depletion step. The affected erroneous section of code is only executed during depletion calculations when the soluble poison concentration changes from one time step to another, which resulted in the error not being discovered until the final months of the project when attempts were made to incorporate the effects of soluble boron into the depletion, and also dues not affect the results reported previously [1-3], all of which used a constant, zero soluble boron concentration. The error was corrected prior to the 
performance of the depletion analyses outlined below which included the effects of soluble boron.

4.6.1. Global Depletion Analysis Methods. Following conventional global depletion methods used in conventional PWRs, the CPM-2 code was used to generate timedependent few-group cross sections for use in the UM2DB code. The UM2DB code is somewhat limited in this application since it has provisions for only a two-dimensional array within its cross section library. The CPM-2/UM2DB system also does not include provisions for a critical boron search to ensure that all few-group cross sections used by UM2DB include the same soluble boron concentration at a given time step. In order to avoid making extensive changes to the codes a different approach was devised.

First, the thermal-hydraulic feedback and local power dependence can be combined by noting that there is a nearly one-to-one relationship between local power level and fuel temperature. By assuming a constant moderator temperature, the MITH cade can be used to determine the fuel temperature as a function of local assembly power. These fuel temperatures are then used as input to the CPM-2 code.

The global BOC critical boron concentration was determined using the CPM-2 and UM2DB codes. This was done by varying the soluble boron concentration used in the CPM-2 calculations which provided cross section input to UM2DB. The assembly level boron concentration was varied until a $k_{\text {eff }}$ value of unity was obtained from the UM2DB calculation. The resulting CPM- $2 k_{\infty}$ value for the mid-enrichment assembly at this global critical boron concentration was then taken as a reference value for depletion of the midenrichment assembly. A boron worth calculation for the mid-enrichment assembly was also performed. The mid-enrichment assembly was then depleted at rated power using a time-dependent soluble boron concentration intended to maintain the reference $k_{\infty}$ value. If the reference $k_{\infty}$ was not maintained, the calculated boron worth was used to revise the estimate of the time-dependent critical boron concentration and the depletion was repeated 
until a time dependent $k_{\infty}$ value acceptably close to the reference $k_{\infty}$ value was obtained. This time dependent soluble boron concentration is only an estimate since it assumes that the mid-enrichment assembly acts as a core average assembly. The error in the critical boron concentration is small near BOC, but can increase somewhat later in core life. If the error becomes too great, a procedure outlined below exists which will correct the boron concentration used in the UM2DB code.

Once an estimate of the time-dependent critical boron concentration is obtained, CPM2 depletion calculations for all of the assembly types in the core are performed at three different power levels which bracket the observed local assembly powers anticipated from the global calculations. The depletion calculations used the power dependent fuel temperatures determined by the MITH code. Typically depletion calculations were performed at 30,100 and $150 \%$ of the rated power condition. The time steps for these calculations were chosen so that for different power levels the steps were identical in terms of time, rather than burnup. Thus, a depletion calculation run at $150 \%$ of rated power must use time steps $50 \%$ longer in terms of burnup than a depletion calculation at rated power. This permits an accurate representation of the time-averaged assembly power and the timedependent soluble boron concentration in the cross section library developed for global calculation.

A revised post processor code was then developed to read the time- and burnupdependent few group cross sections and write the cross section library for input to the UM2DB code. This post processor code was used to reorder the cross sections in the library in such a way that the cross sections are interpolated over burnup at the same point in time and thus the same boron concentration, rather than over burnup and time as would be the case if the global code were used without the restructured few-group cross section library. By performing the global calculations at the same points in time as were used in the assembly level CPM-2 calculations, the effects of the time-dependent solubie boron 
concentration are represented accurately. Through interpolation over burnup the timeaveraged power of each assembly is properly accounted for, with a different material assignment given for each assembly at each time step. At each time step within the global code, the new materials corresponding to cross sections at the new time are shuffled into the core with the previous burnups for these materials provided as input in the global code input deck. Because of the large number of materials involved it was necessary to redimension some of the arrays within the global code UM2DB.

Using the above scheme the $k_{\text {eff }}$ value calculated by the global code should remain close to unity, depending on the accuracy of the original estimate of the time-dependent boron concentration. If the $k_{\text {eff }}$ value deviates excessively from unity, then the mixing feature of the global code can be used to correct the cross sections to give a $k_{\text {eff }}$ closer to unity.

The effects of SSCR withdrawal are first modeled at the assembly level using the restart capability of the CPM-2 code. SSCR withdrawals are calculated for several different exposures, typically $0,6,12$ and $18 \mathrm{GWd} / \mathrm{T}$. A post processor code was used to generate SSCR withdrawal differential cross sections from the results of these SSCR withdrawal restart cases and the base cases with SSCRs inserted. For each SSCR withdrawal sequence, a set of differential cross sections is generated as a function of the exposure experienced since the SSCR withdrawal.

To simulate the withdrawal of SSCRs within the global code, the set of spectral shift differential cross sections whose withdrawal exposures bracket the desired withdrawal exposure are selected. The cross section mixing option of the global code is then used to interpolate these differential cross section sets to the desired withdrawal exposure, and the resulting SSCR withdrawal differential cross section is added to the base cross sections with SSCRs inserted. CPM-2 cross sections for the SSCR withdrawn condition are never used directly. 
The withdrawal of SSCRs can cause significant local power perturbations. Because of this it is necessary to develop a method to account for this. A local power differential cross section is calculated as:

$$
\Delta \Sigma(r, t) / \Delta \mathrm{P}=\left[\Sigma(\mathrm{r}, \mathrm{t})_{\text {high }}-\Sigma(\mathrm{r}, \mathrm{t})_{\text {low }}\right] /\left[\mathrm{P}(\mathrm{r}, \mathrm{t})_{\text {high }}-\mathrm{P}(\mathrm{r}, \mathrm{t})_{\text {low }}\right],
$$

where $\Sigma(r, t)_{\text {high }}$ and $\Sigma(r, t)_{\text {low }}$ are the local cross sections resulting from instantaneous power increases $P(r, t)_{\text {high }}$ and decreases $P(r, t)_{\text {low }}$, respectively, calculated using the CPM2 restart feature. The high and low power are chosen to bracket the power variations of interest. Only one set of local power differential cross sections, independent of exposure and assumed to be valid for the entire core life, is calculated.

4.6.2. SESSR Global Depletion Results. Global depletion analysis of the SESSR was performed using a rated core power of $3618 \mathrm{MWt}$ and average moderator temperature of $590^{\circ} \mathrm{F}$. CPM-2 depletion calculations were carried out at 30,100 and $150 \%$ of rated power. SSCR withdrawals using the CPM-2 code were represented at exposures of 0,6 , 12 and $18 \mathrm{GWd} / \mathrm{T}$. A critical boron concentration at hot, clean full power BOC conditions of $1790 \mathrm{ppm}$ was determined and a boron worth of $-6.6 \mathrm{pcm} / \mathrm{ppm}$ was estimated from the CPM-2 results for the mid-enrichment assembly. Depletion at rated power with all SSCRs inserted results in a critical boron concentration of zero ppm and the attendant need to begin withdrawal of SSCRs at approximately 260 days and an average core exposure of 10 $\mathrm{GWd} / \mathrm{T}$. It was noted that the presence of soluble boron made very little difference in the cycle length calculation, thus validating our previous cycle length calculations, all of which were made for a soluble boron concentration of zero.

Calculations for SSCR withdrawals at exposures of 8 and $10 \mathrm{GWd} / \mathrm{T}$ were performed. In both cases eight SSCRs were withcrawn at one time. The results show, as expected, that high peaking factors can result from SSCR withdrawal, with maximum relative assembly powers of 1.53 and 2.21 resulting after the first and second SSCR withdrawals. This compares with a maximum relative assembly power of 1.29 at BOC 
with all SSCRs inserted. A map of the core loading pattern and relative assembly powers at BOC and after the two SSCR withdrawals is presented in Figure 9. Although the depletion calculations were performed with a global assembly loading pattern different from that of our final design of Section 4.2.2, the global depletion results are typical of SESSR designs considered in our project.

The results of the global SESSR depletion analysis suggest that further work is needed in optimizing the SSCR withdrawal strategy. This might be done by either varying the position within the core of the SSCR withdrawals and by varying the number of SSCRs withdrawn at one time. Because the highest peaking occurs in the assemblies from which SSCRs are withdrawn, this suggests the possibility of withdrawing more SSCRs from the core at one time. Since the average core power remains constant, this may have the effect of spreading the increased peaking over more assemblies, reducing the highest peaking factor within the core.

\section{Methods Development for SESSR Analysis (Task 2)}

Evaluating the adequacy of thermal spectrum LWR neutronics codes for analysis of harder spectrum tight-lattice configurations was one of the goals of this project. We have used the UMLEO and CPM-2 [9] codes for unit-cell and unit-assembly SESJR analyses. UMLEO is a substantially revised version of the LEOPARD infinite medium spectrum code [18], which performs thermal and fast spectrum calculations for a unit cell with an explicit non-lattice region to accommodate non-unit cell regions (water holes, gaps, etc.) in a fuel assembly. CPM-2 is a transport theory code utilizing collision probability (CP) methods to analyze typical PWR and boiling water reactor (BWR) assemblies. The accuracy of these codes in handling various material heterogeneities (thermal and epithermal) for spectra characteristic of a tight lattice has been evaluated. In addition, substantial effort is needed to develop a global analysis capability, including modifications to our multigroup diffusion 


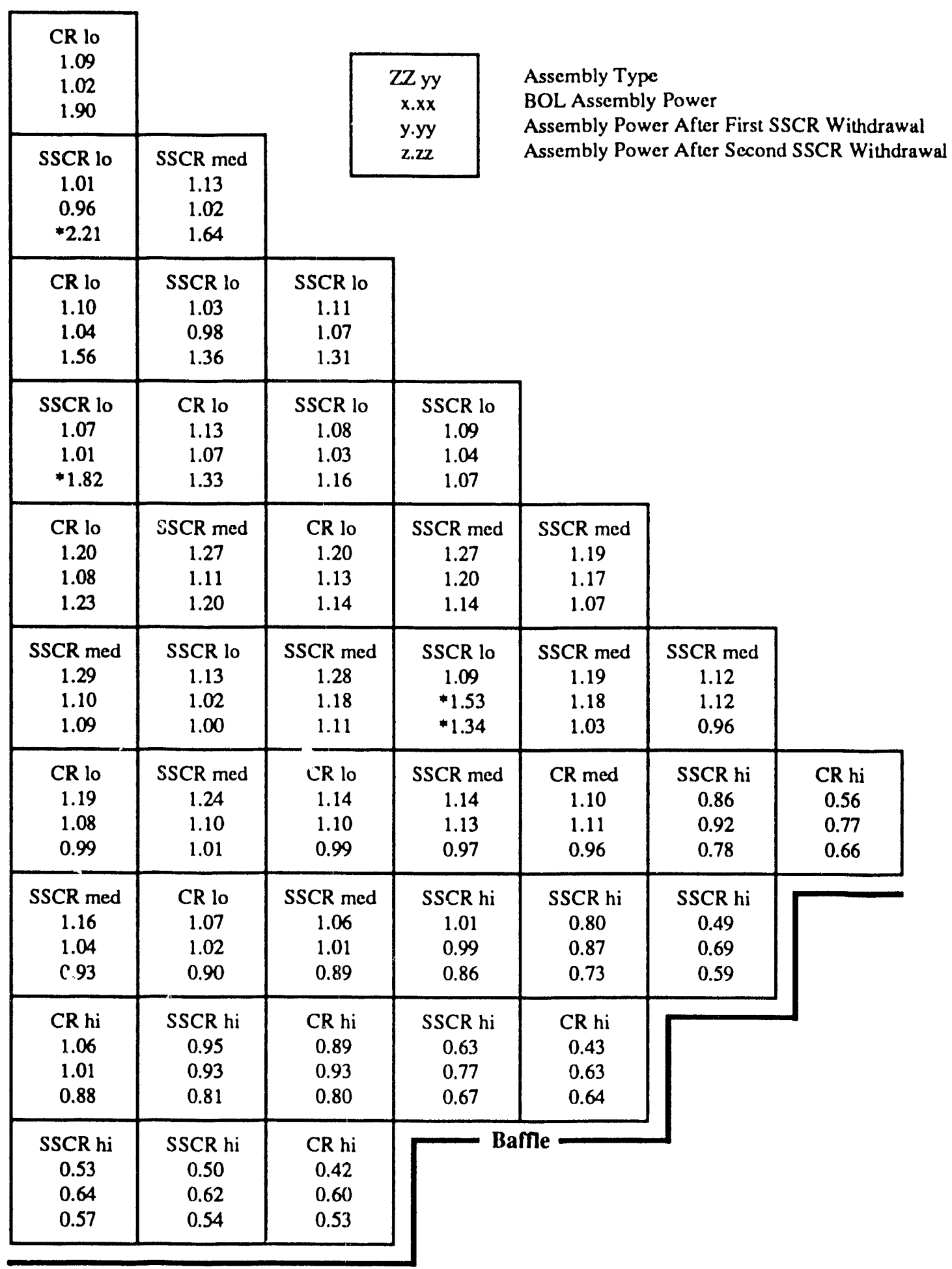

Figure 9. SESSR Core Design and Relative Core Power Map (*Indicates SSCR Withdrawn from Assembly) 
codes UM2DB and UM3DB, which are substantially revised versions of 2DB [12] and 3DB [19], to account for depletion effects due to the withdrawal of the SSCRs. Various items that comprise this overall effort in SESSR methods development are listed below and summarized in the following subsections. The details of these items are contained in the earlier progress reports [1-3].

- Simulation of PROTEUS critical experiments

- Comparison with the VIM Monte Carlo code

- Comparison with the CASMO-3 code

- Generation of reflector cross sections

- Improved resonance absorption models for the SESSR

- Improved collision probability method for the CPM-2 code

- Implementation on advanced computer architectures

- Improved global analysis capability (UM2DB, UM3DB, nodal code)

- Global depletion capability

5.1. Validation of the CPM-2 Code. To assess the applicability of various CPM-2 models for SESSR analysis, we have compared the CPM-2 code with Monte Carlo and deterministic transport theory codes. Comparisons of CPM-2 results for idealized SESSR configurations with results trom the VIM Monte Carlo code [20] are presented in Section 5.1.2. Similar comparisons with the CASMO-3 assembly-level transmission probability code [21] are presented in Section 5.1.3.

5.1.1. Simulation of PROTEUS Critical Experiments. Efforts to benchmark CPM-2 have included simulation of the tight-lattice PROTEUS critical experiments [22-23]. Our efforts on this were discussed in some detail in the first two progress reports [1-2]. The series of light-water high-conversion reactor (LWHCR) critical experiments performed in the PROTEUS zero power facility (Wurenlinger, Switzerland) were designed to provide critical benchmarks for the evaluation of LWR physics codes applied to tight-pitch LWHCR lattices. Reaction rates, reaction rate ratios, and two-rod heterogeneity factors 
calcl lated using CPM-2 agree with the published EPRI-CPM results within $<0.42 \%$ for ${ }^{238} \mathrm{U}$ fission and $<0.20 \%$ for all other reaction rates $\left({ }^{238} \mathrm{U}\right.$ capture, ${ }^{239} \mathrm{Pu}$ fission, and ${ }^{241} \mathrm{Pu}$ fission).

5.1.2. Comparison with the VIM Monte Carlo Code. We have made an extensive effort to compare the CPM-2 code with the VIM code. VIM is a continuous-energy Monte Carlo code used for neutronic analysis of thermal as well as fast spectrum reactors. The VIM cross section library is based on ENDF/B Versions IV and V. We present in Table IX the iatest comparisons of the infinite multiplication factor $k_{\infty}$ from the two codes for typical SESSR pin cells and for an idealized (4×4) SESSR assemtıy shown in Figure 10. Our VIM calculations typically used 90,000 histoiies for each case and hence are subject to nonnegligible statistical fluctuations, which are noted in the tabulated results. The $(4 \times 4)$ assembly configuration in Figure 10 corresponds to F/Ms of 0.80 with a water-filled central tuhe (corresponding to the SSCR withdrawn) and 1.20 with the central tube voided (SSCR inserted).

As shown in the tables, relatively good agreement between VIM and CPM-2 is obtained for well-moderated cells, but the agreement is degraded somewhat at high F/Ms. In our previous report [2] we reported that the agreement between VIM and CPM-2 at high F/Ms could be improved by increasing the number of spatial mesh points used by CPM-2 within the fuel region. Further investigation has shown this result to be incorrect. This investigation has revealed that CPM-2 is not coded correctly for an increased number of spatial mesh points in the fuel region, and that the VIM library which was in use at the time had errors as well, resulting in a fortuitous cancellation of errors.

We have continued our efforts (see Section 5.6) to enable CPM-2 to perform calculations using an arbitrary number of spatial mesh points within the fuel, clad, and moderator regions. Although the effort was not completed prior to the end of the present project, we have been able to obtain some results for pin-cell calculations with an increased 
number of spatial mesh points. We present in Table $X$ a comparison of the VIM results with CPM-2 calculations using one, two and four spatial mesh points within the fuel for pin-cells with varying moderation ratios. As can be seen, the differences resulting from the increasing number of mesh points are extremely small.

We have also obtained an updated nuclear data library for the CPM-2 code (See Section 5.5.4). The present CPM-2 library is based on ENDF/B-III, which may be the

Table IX. Comparison of the CPM-2 and VIM Computer Codes

Comparison of $\mathrm{k}_{\infty}$ for pin-cell calculations

Fuel Temperature $=1000 \mathrm{~K}$, Clad and Moderator Temperature $=300 \mathrm{~K}$

\begin{tabular}{|c|c|c|c|c|}
\hline U-235 Enrichment & F/M Ratio & VIM & CPM-2 & VIM/CPM-2 \\
\hline \multirow{3}{*}{$2.0 \mathrm{w} / \mathrm{o}$} & 0.5 & 1.2332 & 1.2313 & 1.0015 \\
\cline { 2 - 5 } & 0.7 & 1.1825 & 1.1856 & 0.9974 \\
\cline { 2 - 5 } & 1.0 & 1.1179 & 1.1168 & 1.0010 \\
\cline { 2 - 5 } & 1.3 & 1.0520 & 1.0576 & 0.9947 \\
\hline \multirow{3}{*}{$2.5 \mathrm{w} / \mathrm{o}$} & 0.5 & 1.2910 & 1.2895 & 1.0012 \\
\cline { 2 - 5 } & 0.7 & 1.2428 & 1.2374 & 1.0044 \\
\cline { 2 - 5 } & 1.0 & 1.1582 & 1.1632 & 0.9957 \\
\cline { 2 - 5 } & 1.3 & 1.0909 & 1.1011 & 0.9907 \\
\hline
\end{tabular}

Comparison of $\mathrm{k}_{\infty}$ for pin-cell calculations

Fuel Temperature $=300 \mathrm{~K}$, Clad and Moderator Temperature $=300 \mathrm{~K}$

\begin{tabular}{|c|c|c|c|c|}
\hline U-235 Enrichment & F/M Ratio & VIM & CPM-2 & VIM/CPM-2 \\
\hline \multirow{3}{*}{$2.0 \mathrm{w} / \mathrm{o}$} & 0.5 & 1.2645 & 1.2590 & 1.0044 \\
\cline { 2 - 5 } & 0.7 & 1.2194 & 1.2179 & 1.0012 \\
\cline { 2 - 5 } & 1.0 & 1.1465 & 1.1535 & 0.9939 \\
\cline { 2 - 5 } & 1.3 & 1.0913 & 1.0965 & 0.9953 \\
\hline \multirow{3}{*}{$2.5 \mathrm{w} / \mathrm{o}$} & 0.5 & 1.3208 & 1.3182 & 1.0020 \\
\cline { 2 - 5 } & 0.7 & 1.2709 & 1.2707 & 1.0002 \\
\cline { 2 - 5 } & 1.0 & 1.1988 & 1.2008 & 0.9983 \\
\cline { 2 - 5 } & 1.3 & 1.1310 & 1.1410 & 0.9912 \\
\hline
\end{tabular}

Comparison of $k_{\infty}$ for idealized $(4 \times 4)$ lattice calculations

Fuel Temperature $=1000 \mathrm{~K}, \mathrm{Clad}$ and Moderator Temperature $=300 \mathrm{~K}, 2.5 \mathrm{w} / \mathrm{o}$ U-235

\begin{tabular}{|c|c|c|c|c|}
\hline F/M Ratio & $\begin{array}{c}\text { WIM } \\
\text { Chite Boundary } \\
\text { Condition }\end{array}$ & $\begin{array}{c}\text { Perfect Reflector } \\
\text { Boundary Condition }\end{array}$ & CPM-2 & VIM/CPM-2 \\
\hline 0.8 & $1.2207 \pm 0.0020$ & $1.2254 \pm 0.0020$ & 1.2140 & $1.0055 / 1.0094$ \\
\hline 1.2 & $1.1114 \pm 0.0017$ & $1.1113 \pm 0.0020$ & 1.1076 & $1.0034 / 1.0033$ \\
\hline
\end{tabular}




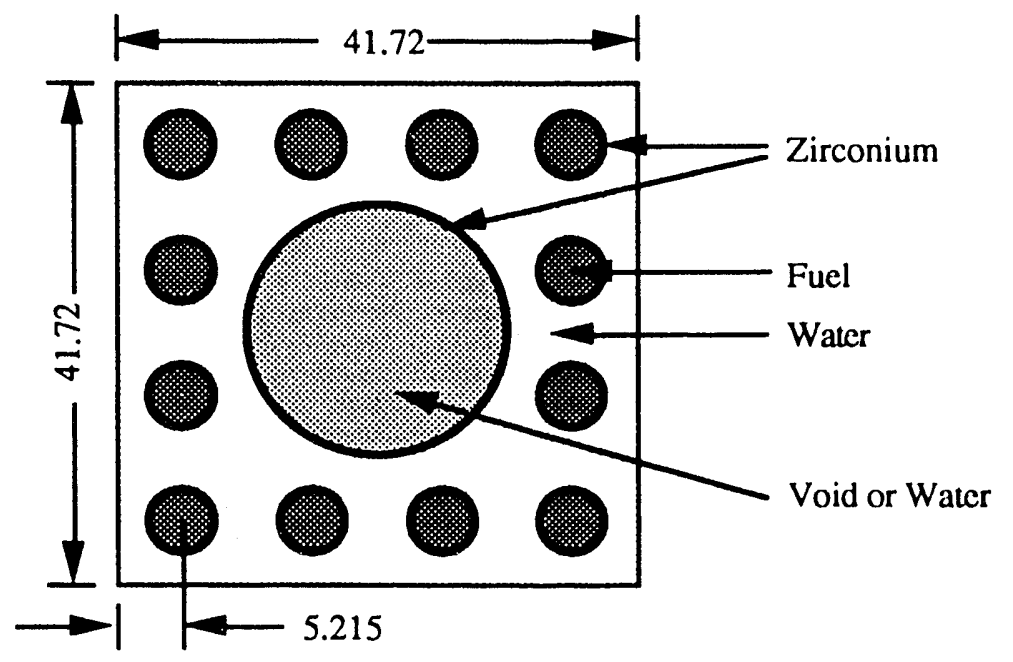

Figure 10. Idealized (4×4) Lattice for Assembly-level Comparison (dimensions in $\mathrm{mm}$ )

cause of some of the discrepancies observed between the VIM and CPM-2 results. Although this effort will be made after the completion of the prasent project, we will modify CPM-2 for the new library for future use.

Table X. Comparison of VIM and CPM-2 with Increased Number of Spatial Regions

Comparison of $k_{\infty}$ for pin-cell calculations

\begin{tabular}{|c|c|c|c|c|}
\hline \multirow{2}{*}{ Fuel } & \multirow{3}{*}{ VIM } & \multirow{2}{*}{\multicolumn{3}{|c|}{ CPM-2 }} \\
\hline & & & & \\
\hline F/M Ratio & & $\begin{array}{c}\text { One Fuel } \\
\text { Region }\end{array}$ & $\begin{array}{l}\text { Two Fuel } \\
\text { Regions }\end{array}$ & $\begin{array}{c}\text { Four Fuel } \\
\text { Regions }\end{array}$ \\
\hline 0.5 & 1.3208 & 1.3184 & 1.3184 & 1.3183 \\
\hline 0.7 & 1.2709 & 1.2707 & 1.2706 & 1.2707 \\
\hline 1.0 & 1.1988 & 1.2007 & 1.2008 & 1.2007 \\
\hline 1.3 & 1.1310 & 1.1408 & 1.1410 & 1.1408 \\
\hline
\end{tabular}

5.1.3. Comparison with the CASMO-3 Code. As a part of our ongoing effort to verify the adequacy of our calculational methods for analysis of the relatively hard neutron flux spectra encountered in our SESSR designs, B\&W Fuel Company (BWFC) has performed assembly-level lattice physics analysis with the CASMO-3 code [21]. As 
detailed in the BWFC report which is attached as Appendix A, we have considered, for this comparison study, one $(4 \times 4)$ lattice geometry and two $(17 \times 17)$ SESSR assembly designs.

We present in Table XI a comparison of results from the CPM-2 and CASMO-3 codes. The $(4 \times 4)$ lattice geometry selected for the comparison is the same idealized heterogeneous assembly geometry used for the VIM vs. CPM-2 comparisons and shown in Figure 10. For more realistic assembly calculations, we include two $(17 \times 17)$ assembly designs. For Case 11 of Table I, we simulate the SSCR insertion and withdrawal at BOC, while for Case 5 of Table I, with SSCRs inserted, we compare fuel depletion characteristics between the two codes. With the SSCR insertion and withdrawal considered also for the $(4 \times 4)$ geometry, we have the following five cases analyzed to compare the CASMO-3 and CPM-2 codes:

Case 1: (4x4) lattice, $F / M=1.2,1$ large SSCR inserted.

Case 2: $(4 \times 4)$ lattice, $F / M=0.8,1$ large SSCR withdrawn.

Case 3: (17x17) assembly, HFP, 104 SSCRs inserted.

Case 4: (17x17) assembly, HFP, 104 SSCRs withdrawn.

Case 5: (17x17) assembly, HFP, 80 SSCRs inserted, fuel depletion to $36 \mathrm{MWd} / \mathrm{kg}$. All cases were analyzed for a $235 \mathrm{U}$ enrichment of $2.5 \mathrm{w} / \mathrm{o}$ and with zero soluble boron concentration.

Table XI. Comparison of CASMO-3 and CPM-2

\begin{tabular}{|c|c|c|c|c|c|c|c|}
\hline \multirow{3}{*}{ Case } & Bumup & \multicolumn{3}{|c|}{$\mathrm{K}_{\infty}$} & \multicolumn{3}{c|}{ Peak Pin Power } \\
\cline { 3 - 8 } & $(\mathrm{MWd} / \mathrm{kg})$ & CPM-2 & CASMO-3 & CASMO/CPM & CPM-2 & CASMO-3 & CASMO/CPM \\
\hline 1 & 0 & 1.1075 & 1.1151 & 1.0069 & 1.008 & 1.006 & 0.998 \\
\hline 2 & 0 & 1.2139 & 1.2117 & 0.9982 & 1.026 & 1.020 & 0.994 \\
\hline 3 & 0 & 1.2950 & 1.2973 & 1.0018 & 1.100 & 1.082 & 0.994 \\
\hline 4 & 0 & 1.2220 & 1.2225 & 1.0040 & 1.045 & 1.020 & 0.976 \\
\hline 5 & 0 & 1.1961 & 1.1981 & 1.0017 & 1.053 & 1.026 & 0.974 \\
\cline { 2 - 8 } & 16 & 0.9869 & 0.9877 & 1.0008 & 1.049 & 1.022 & 0.974 \\
\cline { 2 - 7 } & 32 & 0.9014 & 0.9017 & 1.0003 & 1.040 & 1.017 & 0.978 \\
\hline
\end{tabular}


To summarize the BWFC report of Appendix A, we compare in Table XI lattice $k_{\infty}$ and peak pin power calculated by the two codes for the above five cases, and make a number of observations.

(1) Table XI indicates that the differences in $\mathrm{k}_{\infty}$ between the two codes are generally less than $0.2 \%$, which is acceptably small. Case 1 , however, is an exception, with a difference of $\sim 0.7 \%$. This is perhaps understandable, since Case 1 represents a highly heterogeneous lattice geometry with one large SSCR located in the center of a $(4 \times 4)$ lattice, as shown in Figure 10.

(2) Although the differences in $\mathrm{k}_{\infty}$ between the codes are generally acceptably small, the corresponding differences in two-group constants can be as large as $-5 \%$. Further study is necessary to understand these large differences, which may be partly due to differences in cross section libraries currently used with the codes.

(3) For all cases considered, the peak pin power calculated by the CASMO-3 code is less than that calculated by the CPM-2 code, with a maximum difference of $\sim 2.5 \%$. At this point, we have no explanation for this discrepancy.

(4) Although the reactivity trend for Case 5 as a function of fuel depletion indicates an excellent agreement beiwcen the codes, the ${ }^{235} \mathrm{U}$ concentration at large fuel burnup can be different by $\sim 2 \%$ between the codes. In addition, apparently because the CPM- 2 code does not explicitly represent the buildup of ${ }^{239} \mathrm{~Np}$, with a half-life of 2.35 days, the CPM-2 code significantly overpredicts the ${ }^{239} \mathrm{Pu}$ concentration during the early periods of fuel depletion.

As noted in Section 5.5.4, and together with other improvements in the CPM-2 code discussed in Section 5.6, an effort is underway to update the CPM-2 cross section library to an ENDF/B-IV or V basis. Once the cross section library is updated, the CASMO-3 results will be used again to see if we can resolve some of the significant differences noted above. 
5.2. Generation of Reflector Cross Sections. Neither one of our lattice physics codes, UMLEO or CPM-2, can adequately model the presence of the core baffle in generation of reflector constants for global multigroup diffusion (MGD) theory calculations. For this reason, we need to perform global transport theory calculations explicitly representing the baffle and the surrounding water reflector, and generate effective fast-group diffusion constants so that neutron leakage at the core-reflector interface can be preserved between the transport and diffusion theory calculations.

With the XSDRN-PM transport theory code [24], we have modeled the core with three radial enrichment zones and the reflector with two zones, separately representing the stainless steel baffle and water. Volume-averaged number densities needed for XSDRNPM input for different materials in the core were calculated with the CPM-2 and UMLEO codes. The NITAWL-S code [25] was used to process data from a 27-group library into a working library for use with XSDRN-PM. The NITAWL-S code also performed resonance absorption calculations using the Nordheim integral method. The XSDRN-PM code was then used to collapse the fine-group cross section data, homogenized over the baffle and water, into two broad groups. The resultant reflector cross sections were then used, along with CPM-2 assembly-average cross sections, in global power distribution calculations with the UM2DB code. The fast-group diffusion constant was iteratively modified in the UM2DB calculations to preserve the albedo [26] at the core-reflector interface, which was calculated with the XSDRN-PM code.

To assess the adequacy of our overall global calculation method, we first modeled the Millstone Unit 3 reactor using the combination of the XSDRN-PM and UM2DB codes as discussed above. The UM2DB calculation, with a $(2 \times 2)$ mesh per assembly and an unadjusted fast-group reflector constant, showed differences of up to $14 \%$ in the relative core power distribution from the corresponding results of the MNP-3 FSAR [11]. When the fast-group diffusion constant was iteratively modified in UM2DB calculations to 
preserve the XSDRN-PM albedo at the core-reflector interface, again with a $(2 \times 2)$ mesh per assembly, power distribution errors were reduced to $6 \sim 7 \%$, as shown in Figure 11 . The results are generally improved when a $(6 \times 6)$ mesh is used with the UM2DB code, also shown in Figure 11. We also include in Figure 11 the power distribution obtained with the CASTOR variational nodal diffusion code, which is described in Section 5.7.

The sarne procedure involving the XSDRN-PM and UM2DB codes was followed to generate reflector cross sections and core power maps for the reference SESSR design shown in Figure 7. The residual errors observed for the Millstone case in Figure 11, both in the (6x6) UM2DB and CASTOR calculations, indicate perhaps the limitations of our homogeneous assembly representation as well as the approximations inherent in our use of a single set of reflector constants for the entire baffle-reflector region. Further effort will be necessary to improve our ability to represent the baffle-reflector geometry, as an integral part of the MGD method developments discussed further in Section 5.7.

5.3. Development of a Fuel Cycle Code (CYCLE). The CYCLE code estimates the fuel cycle length for the SESSR with one or multiple enrichment zones. The cycle length is estimated through calculation of $k_{\infty}$ as a function of fuel burnup subject to withdrawal of SSCRs. The code uses tables of $k_{\infty}$ vs. burnup for various SSCR withdrawal sequences and simulates, through interpolation between the $k_{\infty}$ values for different sequences, gradual withdrawal of SSCRs as fuel depletes and core reactivity decreases. For multiple enrichment zones, the $k_{\infty}$ values of different zones are mixed to yield a core-average $k_{\infty}$ at every burnup step, with the assumption of equal power sharing among the regions. Through this approach, the code can simulate a multi-cycle approach to an equilibrium cycle as well as a batch core depletion. The CYCLE code is described in more detail in Appendix A of Ref. 2. 


\begin{tabular}{|c|c|c|c|c|c|}
\hline $\begin{array}{l}1.06 \\
1.05 \\
1.05 \\
1.06\end{array}$ & & & $w . w w$ & \multirow{3}{*}{\multicolumn{2}{|c|}{$\begin{array}{l}\text { FSAR Value } \\
\text { CASTOR }(2,4) \\
\text { UM2DB }(2 \times 2) \text { mesh/assembly } \\
\text { UM2DB }(6 \times 6) \text { mesh/assembly }\end{array}$}} \\
\hline $\begin{array}{l}0.96 \\
0.95 \\
0.91\end{array}$ & $\begin{array}{l}1.07 \\
1.06 \\
1.06\end{array}$ & & $\begin{array}{l}x . x x \\
y . y y \\
z . z z\end{array}$ & & \\
\hline 0.97 & 1.07 & & & & \\
\hline $\begin{array}{l}1.08 \\
1.07 \\
1.07 \\
1.08\end{array}$ & $\begin{array}{l}0.96 \\
0.97 \\
0.93 \\
0.99\end{array}$ & $\begin{array}{l}1.09 \\
1.08 \\
1.09 \\
1.09\end{array}$ & & & \\
\hline $\begin{array}{l}0.98 \\
1.00 \\
0.95 \\
1.01\end{array}$ & $\begin{array}{l}1.10 \\
1.10 \\
1.10 \\
1.10\end{array}$ & $\begin{array}{l}0.98 \\
1.00 \\
0.96 \\
1.01\end{array}$ & $\begin{array}{l}1.12 \\
1.12 \\
1.14 \\
1.13\end{array}$ & & \\
\hline $\begin{array}{l}1.14 \\
1.15 \\
1.16 \\
1.15\end{array}$ & $\begin{array}{l}1.01 \\
1.03 \\
0.98 \\
1.04\end{array}$ & $\begin{array}{l}1.12 \\
1.12 \\
1.13 \\
1.12\end{array}$ & $\begin{array}{l}1.01 \\
1.03 \\
1.00 \\
1.04\end{array}$ & $\begin{array}{l}1.25 \\
1.24 \\
1.32 \\
1.27\end{array}$ & \\
\hline $\begin{array}{l}1.10 \\
1.13 \\
1.09 \\
1.14\end{array}$ & $\begin{array}{l}1.17 \\
1.19 \\
1.19 \\
1.18\end{array}$ & $\begin{array}{l}1.01 \\
1.03 \\
0.99 \\
1.03\end{array}$ & $\begin{array}{l}1.10 \\
1.10 \\
1.12 \\
1.09\end{array}$ & $\begin{array}{l}0.93 \\
0.94 \\
0.94 \\
0.94\end{array}$ & $\begin{array}{l}1.07 \\
1.04 \\
1.13 \\
1.04\end{array}$ \\
\hline $\begin{array}{l}1.16 \\
1.19 \\
1.20 \\
1.18\end{array}$ & $\begin{array}{l}1.11 \\
1.15 \\
1.10 \\
1.14\end{array}$ & $\begin{array}{l}1.11 \\
1.11 \\
1.13 \\
1.09\end{array}$ & $\begin{array}{l}0.96 \\
0.95 \\
0.94 \\
0.94\end{array}$ & $\begin{array}{l}0.88 \\
0.83 \\
0.88 \\
0.82\end{array}$ & $\begin{array}{l}0.56 \\
0.56 \\
0.55 \\
0.52\end{array}$ \\
\hline $\begin{array}{l}0.92 \\
0.89 \\
0.90 \\
0.87\end{array}$ & $\begin{array}{l}0.96 \\
0.92 \\
0.96 \\
0.91\end{array}$ & $\begin{array}{l}0.93 \\
0.89 \\
0.91 \\
0.88\end{array}$ & $\begin{array}{l}0.65 \\
0.60 \\
0.61 \\
0.58\end{array}$ & & \\
\hline
\end{tabular}

Figure 11. Relative Core Power Map for Millstone Unit 3

(One-Eighth Core Shown) 
5.4. Lumped Fission Product Correlation for UMLEO. New lumped fission product correlations were developed for UMLEO by using more detailed calculations with the burnup code EPRI-CINDER [27]. These new correlations were developed for UMLEO for all four energy groups and yield excellent results when compared to EPRI-CINDER. Appendix B of Ref. 2 contains the detailed report on this effort.

5.5. Improved Resonance Absorption Models for the SESSR. The tight-lattice SESSR geometry has a number of important reactor physics ramifications associated with a harder spectrum which increases epithermal reaction rates at the expense of thermal reaction rates. This spectral effect becomes more pronounced towards the EOC, indicating the importance of fission products and the buildup of the lutonium and other higher actinide isotopes. Coupled with the presence of heterogeneities introduced by the SSCRs in the fuel assembly, this spectral hardening effect requires careful examination of a number of approximations utilized in LWR analysis where the predominance of thermal reaction rates allows one to neglect (or model crudely) a number of epithermal phenomena. It is clear from recent international studies $[28,29]$ that among the principal uncertainties in the analysis of tight-lattice designs are the treatment of resonance absorption, especially for ${ }^{238} \mathrm{U}$ and ${ }^{239} \mathrm{Pu}$, and the insufficient quality of the evaluated nuclear data used for the spectrum calculation.

In addition to the efcects of the hardened spectrum, the considerable spectral changes associated with SSCR muvement brings into question the adequacy of utilizing a single set of multigroup cross sections, including a fixed set of intermediate resonance parameters, to model both the hard spectrum (with SSCRs inserted) and the later softened spectrum (when SSCRs are withdrawn). We performed preliminary Monte Carlo simulations for simplified pin cells which indicated that the multigroup cross sections are sensitive to the intra- and inter-group fluxes. Relative collision rates are decreased by as much as $20-25 \%$ in the 
epithermal groups in the fuel when the F/M is decreased from 0.7 to a typical PWR value of 0.54 , compensated for by a similar increase in the collision rates in the thermal region in the moderator. Furthermore, in the 69-group CPM-2 structure, it is also observed that the total cross sections in some individual resonance groups change by several percent due to changes in both inter- and intra-group flux shapes. Although preliminary, these results again suggest the need for an improvement in the multigroup CPM-2 methodology.

5.5.1. CPM-2 Approach. The CPM-2 code determines effective resonance integrals using interpolation from tabulated homogeneous resonance integrals based on the intermediate resonance approximation [9]. Homogeneous resonance integrals are tabulated as functions of temperature and a potential cross section which includes the intermediate resonance parameter. An equivalence theorem, with a two-term rational approximation, is used to relate the heterogeneous problem to an equivalent homogeneous problem. A first order correction for the interaction associated with the presence of several nuclides in the same material is used. The resonance region considered is from $4 \mathrm{eV}$ to $9118 \mathrm{eV}$, represented by 14 groups out of the 69 -group structure, and excludes the $1.05 \mathrm{eV} 240 \mathrm{Pu}$ and $0.30 \mathrm{eV} 239 \mathrm{Pu}$ resonances. These low lying resonances are treated separately by concentrating 12 thermal groups around the $240 \mathrm{Pu}$ resonance and 5 groups around the ${ }^{239} \mathrm{Pu}$ resonance.

5.5.2. Multiband Method for Resolved Resonances. Several alternative resonance treatments were considered. A hyper-fine energy mesh treatment with several tens of thousands of groups in the region $0.1 \mathrm{eV}$ to $\sim 9 \mathrm{keV}$ along with a CP-based flux calculation would certainly provide an accurate model. Another alternative is to perform the entire spectrum calculation using a Monte Carlo simulation. The cost of these treatments, however, would be unreasonable. Another possibility is to use Nordheim's integral treatment (as in the NITAWL code) which solves the slowing down equation numerically and only requires $\sim 3$ times the CPU time as a table look-up method [29]. 
Another potential treatment which we investigated is the multiband method, derived from the probability table method originally developed for Monte Carlo calculations in the unresolved resonance region [30]. In the normal multigroup method, one can attempt to improve the transport model by using more energy groups. This is accomplished by further subdividing each energy group. Within each energy group all neutrons interact with the same cross section. In the multiband method, each group is further subdivided, not into smaller energy intervals, but rather into total cross section ranges. The resulting equations allow the neutrons within the same group to interact with more than one total cross section.

Functionally, multiband cross sections are similar to multigroup cross sections $w$ ith the typical integral over the energy group but also with a weighted integral over a cross section band. The multiband equations can be treated as an expansion of additional groups within the multigroup structure and can be used directly in existing multigroup calculational schemes by expanding the group structure to accommodate multibands in the region of interest. In both the multiband and multigroup approaches, a weighting function must be assumed to compute the cross sections. Our initial studies verified that, for the cases studied, the multiband results are less sensitive to the assumed weighting function than are the multigroup results. This result indicates potential promise in extending the multiband method to better represent resolved resonances as an enhancement to the CPM-2 multigroup resonance treatment.

Recent investigations revealed that the derivation of multiband parameters from the integro-differential form of the transport equation [30] is strictly valid only for homogeneous media. The heterogeneous boundary conditions cited in this reference have not been verified. We have recently derived an integral form of the transport equation which is valid for heterogeneous media. This integral equation has the same form as a conventional integral equation but with a more complicated kerr.ti. it appears that solution 
of this integral equation should be possible utilizing a standard integral transport algorithm provided the kernel can be suitably defined. These results hold the promise that a multiband $\mathrm{CP}$ formulation may be possible.

5.5.3. Hybrid Monte Carlo/Collision Probability Methods. The advantages and disadvantages of Monte Carlo methods versus deterministic methods for solving the transport equation are subjects of debate, with the usual observation being that Monte Carlo may be extremely accurate, but that it comes at a price. However, in many cases the ability of Monte Carlo to model even the most complex geometries and physical processes makes it the method of choice, and we are developing an interesting variation on a Monte Carlo method to analyze resonance absorption in the SESSR spectrum calculations.

The idea currently under development is to couple the CP and Monte Carlo methods in space and energy, taking advantage of the best features of each -- the ability of the deterministic method to quickly predict neutron density distributions, and that of the Monte Carlo method to handie the resonance absorption, including the effects of spatial heterogeneities. This is a hybrid method, with Monte Carlo used in particular regions of phase space, the CP method used in the other regions of phase space, and with suitable coupling between the two methods across the phase space boundaries. A challenging aspect of our approach is to develop a simple model which leads to sufficiently accurate results using the least amount of computational time. This includes the details of how the Monte Carlo and deterministic methods are implemented in each of their regions, as well as the coupling terms that are used to link the regions in phase space. Recent literature surveys indicate that a spatial-spectral coupling of $\mathrm{CP}$ and Monte Carlo methods has not been previously developed.

5.5.4. Improved Cross Section Library for CPM-2. As mentioned above, one of the principal uncertainties in the analysis of tight-lattice designs is the insufficient quality of the evaluated nuclear data used for the spectrum calculation. A recognized potential deficiency 
with our CPM-2 analyses in this project was the cross section files which we had available for use in CPM-2. Our analyses were performed with a 69-group CPM-2 library based on ENDF/B-III data for 65 isotopes [31]. We have recently acquired a 70-group library designed for use with the CASMO code from Studsvik of America, Inc. [32]. The group structure of this new CASMO library is similar to the structure in CPM-2 and we are attempting to modify our version of CPM-2 to utilize the new CASMO library, which is based on ENDF/B-V data for 87 isotopes. In particular, the new library has more and much higher quality evaluated nuclear data for the higher actinide isotopes which are of greater importance in the spectral shift reactor. Also, since the library is derived from ENDF/B-V data, the library should be more comparable with the VIM library which is derived from the same eviluated data file.

5.5.5. Improved Version of VIM. We have recently acquired from Argonne National Laboratory (ANL) a new version of the VIM Monte Carlo code. This new version includes several enhancements which will improve the ability to compare methodologies between CPM-2 (or CASMO) and VIM. The new VIM has the ability to edit the scattering matrices which are necessary for the multigroup CP treatment in CPM-2. As a result, it should be possible to run a VIM simulation and edit cross sections in the 69-group CPM-2 structure for use in spectrum calculations. Work to facilitate this is in progress. In addition, a code called ISOVIM has been developed at ANL. This code is designed to process multigroup cross section data from a CASMO (or CPM-2) simulation into a VIM material cross-section file. Thus, one could run a CPM-2 simulation and use the resulting multigroup cross sections in VIM to run a "multi-group" Monte Carlo simulation. Both the latest version of VIM and thie cross section processing code ISOVIM are designed to facilitate comparison of the $\mathrm{CP}$ method with the Monte Carlo method independent of the cross section base. This allows one to use cross sections derived from either the VIM or the CPM-2 libraries in either code. 
5.6. Improved Collision Probability Method for CPM-2. Effort has been underway to improve the $\mathrm{CP}$ calculation by allowing a fine mesh $\mathrm{CP}$ description for the fine-group pin cell calculations at the assembly level. While we do not now expect such fine mesh capability (which is possible for a pin cell calculation but not an assembly calculation) to improve the agreement between the CPM-2 and VIM simulations, it will pen it additional capabilities to CPM-2, including the explicit calculation of gadolinium depletion. This effort includes not only redimensioning a number of arrays within the code, but also removing impediments to the solution of a more generalized problem within the code. As noted in Section 4.6, we uncovered an error in the CPM-2 code which results in incorrect calculations for assembly-level depletion cases with variable boron concentrations. This error has been corrected as described in detail in Section 4.6. The need to correct this error prior to performing the global depletion calculations prevented completion of the improved collision probability method before the end of the project. Some results were, however, obtained for pin-cell calculations with the improved method, as reported in Section 5.1.2.

5.7. Improved Global Analysis Capability. Our effort in improving the global analysis capability has focused on two areas -- (1) global depletion capability, which is discussed in Section 4.6 and (2) more accurate and efficient coarse mesh methods for the global MGD calculation which will be discussed here.

This effort has included a preliminary assessment of the applicability of the CASTOR nodal diffusion code [33] to the SESSR analysis. As summarized later in this section, the CASTOR code calculates global flux and power distributions more accurately than the UM2DB code. The CASTOR scheme will be examined more thoroughly in the near future, and homogenization and flux reconstruction techniques taken from NEM [34] and SIMULATE-3 [35,36] will be incorporated into this code. Another effort involves developing an improved coarse-mesh method which incorporates homogenization techniques and flux reconstruction methods [34-36] into a response matrix formalism [37- 
39], which has yielded promising results [40]. Accurate coarse-mesh methods based on this technique will allow repeated global reactor calculation: with different fuel loading patterns at a nominal cost .

The CASTOR code uses Kantorovich's variational method [33] to solve the MGD equation in two and three dimensions. In this high-order variational scheme, the neutron flux distribution within a rectangular node is approximated by Legendre expansions in transverse coordinates and quasi-one-dimensional nodal equations are formulated. Coupling between adjacent nodes is achieved through boundary values of transverse direction moments. Due to orthogonality of Legendre polynomials, the nodal equations for each direction are decoupled from those for transverse directions. Together with a Legendre expansion for the source distribution, the solution is numerically obtained in terms of interface current moments.

The code has been benchrnarked against two well-known test problems including the two-dimensional Biblis-1300 test problem [41]. The test case simulates an unrodded PWR configuration, with 7 sets of homogenized assembly cross sections and a set of reflector constants specified in standard two-group format. A series of CASTOR calculations was performed with different meshes and various orders of flux and source expansions. A comparison between CASTOR results and the reference solution for this two-dimensional benchmark problem is presented in Figure 12. The CASTOR results were obtained with one node per assembly but with two different combinations of the flux expansion order $n=$ 0,2 , and source expansion order $m=2,4$. We also include in Figure 12 the results of UM2DB calculations with a $(2 \times 2)$ and $(6 \times 6)$ mesh per assembly.

We note that the 0th-order flux expansion, $n=0$, in CASTOR is equivalent to standard nodal methods with a flat leakage approximation, while the first- and second-order expansions, $n=1$ and 2, can be considered analogous to standard nodal methods with linear and quadratic leakage approximations, respectively. The CASTOR results converge 


\begin{tabular}{|c|c|c|c|c|c|}
\hline $\begin{array}{r}1.091 \\
-4.40 \\
+0.03 \\
-7.68 \\
+2.53 \\
\end{array}$ & & & \multirow{3}{*}{$\begin{array}{c}\text { w.ww } \\
\text { u.uu } \\
\text { x.xx } \\
\text { y.yy } \\
\text { z.zz }\end{array}$} & & $\begin{array}{l}\text { Power, Reference Solution } \\
\text { CASTOR }(0,2)\end{array}$ \\
\hline $\begin{array}{r}1.102 \\
-6.70 \\
-0.01 \\
-11.8 \\
+0.90\end{array}$ & $\begin{array}{r}1.118 \\
-3.61 \\
+0.03 \\
-7.34 \\
+2.34\end{array}$ & & & & $\begin{array}{l}\text { CASTOR }(2,4) \\
\text { UM2DB }(2 \times 2) \\
\text { UM2DB }(6 \times 6)\end{array}$ \\
\hline $\begin{array}{r}1.243 \\
-2.95 \\
+0.02 \\
-6.47 \\
+2.00\end{array}$ & $\begin{array}{r}1.134 \\
-3.67 \\
+0.01 \\
-10.8 \\
+0.56\end{array}$ & $\begin{array}{r}1.122 \\
-2.89 \\
+0.03 \\
-5.64 \\
+1.86\end{array}$ & & & \\
\hline $\begin{array}{r}1.221 \\
-3.22 \\
0.00 \\
-8.84 \\
+0.33\end{array}$ & $\begin{array}{r}1.224 \\
-2.56 \\
+0.02 \\
-5.06 \\
+1.41\end{array}$ & $\begin{array}{r}1.105 \\
-2.69 \\
-0.01 \\
-8.27 \\
+0.03\end{array}$ & $\begin{array}{r}1.161 \\
-0.75 \\
+0.02 \\
-1.43 \\
+1.28\end{array}$ & & \\
\hline $\begin{array}{r}1.089 \\
-2.56 \\
+0.01 \\
-5.21 \\
+0.32\end{array}$ & $\begin{array}{r}1.068 \\
-2.82 \\
0.00 \\
-8.59 \\
-0.93\end{array}$ & $\begin{array}{r}1.120 \\
-0.96 \\
+0.02 \\
-2.14 \\
+0.52\end{array}$ & $\begin{array}{r}1.039 \\
-0.27 \\
-0.01 \\
-3.59 \\
-0.43\end{array}$ & $\begin{array}{r}1.123 \\
+2.24 \\
0.00 \\
+5.47 \\
+1.04\end{array}$ & \\
\hline $\begin{array}{l}0.982 \\
-2.12 \\
-0.01 \\
-9.50 \\
-3.10\end{array}$ & $\begin{array}{r}1.032 \\
-1.25 \\
+0.01 \\
-3.31 \\
-0.88\end{array}$ & $\begin{array}{l}0.924 \\
-1.34 \\
-0.01 \\
-6.55 \\
-2.61\end{array}$ & $\begin{array}{r}0.950 \\
+1.22 \\
-0.01 \\
+0.84 \\
+0.39\end{array}$ & $\begin{array}{r}0.993 \\
+4.43 \\
-0.02 \\
+7.17 \\
+0.03\end{array}$ & $\begin{array}{r}1.199 \\
+8.85 \\
-0.02 \\
+11.5 \\
+1.18\end{array}$ \\
\hline $\begin{array}{r}1.095 \\
-0.38 \\
0.00 \\
-1.32 \\
-1.20\end{array}$ & $\begin{array}{r}1.072 \\
-0.14 \\
0.00 \\
-0.77 \\
-1.14\end{array}$ & $\begin{array}{r}0.931 \\
+0.44 \\
0.00 \\
+1.89 \\
-0.64\end{array}$ & $\begin{array}{r}0.765 \\
+1.68 \\
-0.03 \\
+3.79 \\
-0.89\end{array}$ & $\begin{array}{r}0.874 \\
+7.48 \\
-0.02 \\
+18.5 \\
+0.65\end{array}$ & $\begin{array}{r}0.684 \\
+8.40 \\
-0.03 \\
+27.3 \\
+1.13\end{array}$ \\
\hline $\begin{array}{r}1.015 \\
+0.18 \\
-0.02 \\
+5.17 \\
-1.25\end{array}$ & $\begin{array}{r}0.971 \\
+0.40 \\
-0.01 \\
+5.79 \\
-1.15\end{array}$ & $\begin{array}{r}0.825 \\
+2.50 \\
-0.01 \\
+6.77 \\
-0.92\end{array}$ & $\begin{array}{r}0.545 \\
+4.06 \\
-0.03 \\
+12.6 \\
-0.56\end{array}$ & & \\
\hline
\end{tabular}

Figure 12. CASTOR and UM2DB Relative Core Power Distributions for Biblis-1300 (One-Eighth Core Shown) 
rapidly to the reference solution as the flux expansion order increases, and the second-order CASTOR results are more accurate than the corresponding standard nodal results by an order of magnitude [33]. The CASTOR results also compare well with a high-order finite element response matrix method mentioned earlier [37].

The UM2DB results in Figure 12 indicate that large errors in power distributions may occur with coarse-mesh finite-difference calculations. For a $(2 \times 2)$ mesh per assembly, a maximum error of $27.3 \%$ is noted in the UM2DB power distribution, with a standard deviation of $8.9 \%$. With a $(6 \times 6)$ mesh per assembly, the maximum error and standard deviation are reduced to $3.1 \%$ and $1.3 \%$, respectively. The UM2DB calculations suggest that perhaps the $(6 \times 6)$ mesh is the minimum detail necessary for acceptable accuracy in PWR power distribution calculations.

\subsection{Implementation of CPM-2 on Advanced Computer Architectures. The CPM-2} code has been implemented on a parallel/vector supercomputer, the IBM 3090/600E, as was reported in [2]. This effort included both vectorization and parallelization techniques and resulted in substantial speedups on the IBM 3090/600E computer at the Cornell National Supercomputer Facility. These enhancements have resulted in a reduction of 7 in CPU time and 20 in wall-clock time for CPM-2. The subsequent implementation of a transfer matrix treatment (involving transmission, collision, and escape probabilities) in place of the pure collision probability treatm $\mathrm{nt}$ in CPM-2 has resulted in a further increase in efficiency -- the new method has resulted in a decrease in CPU time by a factor of 40 and a corresponding decrease in wallclock time by a factor of 50 , both compared with the original CPM-2 code. The transfer matrix approach will allow the analysis of more than one assembly with CPM-2, since the restriction of zero current boundaries is removed with this approach. Anisotropic scattering has also been implemented into this new version of CPM-2. This effort is described in Refs. 42 and 43. 
5.9. Development of Global CPM-2 Capability. The CPM-2 code contains the limitations of infinite lattice geometry and isotropic scattering. These limitations inhibit the use of CPM-2 for global (multi-assembly or reactor level) calculations. To address this, a new method based on using collision, escape, and transmission probabilities, was developed to solve the integral neutron transport equation for 2-D assembly geometries with linearly anisotropic scattering. The new version of CPM-2 (called TECPM-2) has been developed and tested, and appears capable of performing multi-assembly, reactor level calculations in a reasonable amount of time. However, we have deferred the effort to piece together the assembly calculations to form a global method, and it is unlikely that this effort will be resumed in the near future.

5.10. Global Depletion Method. As noted earlier, the global depletion analysis for the SESSR represents a difficult problem. The global depletion analysis must not only consider the effects of the core average power, local assembly power, thermal-hydraulic feedback and the time-dependent critical boron concentration as in a conventional PWR, it must also consider the effects of the time-dependent SSCR insertion. A method for performing this analysis using the CPM-2 and UM2DB codes with minimal modifications has been developed. A detailed description of this method is given in Section 4.6.1.

5.11. Optimal Fuel Depletion Strategy. This task involves development of systematic optimal control algorithms to determine the placement of SSCRs within a fuel assembly, the loading of fuel assemblies in the core, and the burnup-dependent withdrawal of SSCRs. As the first step in tackling this complex task and as summarized in Section 4.6.1, we have developed a global fuel depletion capability with the UM2DB code that accounts for SSCR withdrawal sequences accurately. We have also investigated a number of optimization schemes that could be applied to SESSR fuel depletion analysis, but we defer further studies on this task to a later date. 


\section{Verification of SESSR Design for PWR Use (Task 3)}

As part of the collaborative effort between B\&W Fuel Company and the University of Michigan, BWFC has performed CASMO-3 calculations for several SESSR configurations for comparison with our CPM-2 and VIM results. As summarized in Section 5.1.3, the agreement between CASMO-3 and CPM- 2 results is generally acceptable, but there are a number of areas that need further study. A full report by BWFC on their CASMO-3 study is included as Appendix A.

\section{Summary}

The previous sections summarized our effort throughout the project in design and analysis of the SESSR concept as an acceptable alternative to conventional PWR design. Since the preceding discussion was not explicitly coupled to the tasks identified in Figure 2 that were carried out during the grant, a brief summary of the progress made on each task is given below.

Task 1.1. Nuclear design of the SESSR fuel assembly. This task is complete. The reference SESSR design is discussed in Section 4.2.1.

Task 1,2. Global core analysis of the SESSR concept. This task is complete for BOC and is discussed in Section 4.2.2. The global depletion analysis has been initiated and verified for a few time steps, as presented in Section 4.6.

Task 1.3. Thermal-hydraulic analysis. A single-channel analysis was performed for several design configurations and the results are discussed in Section 4.3. The original intent was to have B\&W perform a subchannel analysis of the SESSR design; however, this effort was deferred and replaced by a comparison of the B\&W lattice analysis methods (CASMO-3) with those employed for our analysis (CPM-2). 
Task 1.4. Fuel cycle cost analysis. Fuel cost and conversion ratio calculations have been performed for two enrichments for our reference SESSR design. The calculations are based on assembly-level fuel depletion analysis and are summarized in Section 4.4.

Task 2,1,1. Comparison of CPM-2 with critical experiments. This work was completed and reported in Refs. 1 and 2.

Task 2,1.2. Fission product model for CPM-2. The model currently in CPM-2 was found to be similar to that in EPRI-CINDER, since the same isotopes and chains are used, hence there was no reason to pursue this task.

Task 2,13. Triangular lattice capability for CPM-2. This task was first proposed on the basis that ACR designs used relatively tight lattices and a hexagonal lattice would be needed to increase $\mathrm{F} / \mathrm{M}$ into the range currently under consideration by other groups examining the spectral shift concept. However, we found early in our studies that a relatively loose lattice was best for the SESSR concept and there was no need to go to a hexagonal lattice. It is interesting to note that other groups [8] are beginning to realize the advantages of a looser lattice, and our lead may be followed by other design groups.

Task 2,1,4. Improved collision probability calculation. This effort, allowing spatially-refined collision probability calculations and correction of an error in handling of depletion cases, has been partially completed, as reported in Sections 5.1.2 and 5.6.

Task 2,1,5. Comparison with the VIM Monte Carlo Code. Comparisons with the VIM Monte Carlo code have been presented and are essentially complete. When an updated CPM-2 library becomes available, additional comparisons will be performed. These comparisons are discussed in Section 5.1.2.

Task 2,1,6. Comparison with the CASMO-3 Code. Comparisons with the CASMO3 code have been presented and are essentially complete, as presented in Section 5.1.3. Again, when an updated CPM-2 library becomes available, additional comparisons will be performed. 
Task 2.2. UMLEO effort. This task consisted of a number of items to improve the UMLEO code for SESSR analysis and the major improvement, the development of the lumped fission product model based on EPRI-CINDER, is complete. This is discussed in detail in Appendix B of Ref. 2.

Task 2.3. UM2DB and UM3DB effort. The primary effort here was to incorporate SSCR-dependent and depletion-dependent cross sections into the macroscopic burnup library currently utilized by both codes. This has been complete and preliminary depletion calculations indicate that it is working correctly, as discussed in Section 4.6.

Task 2.4. Improved resonance absorption models. Possible methodologies for improved resonance absorption treatments have been discussed in Section 5.5.

Task 2.5. Improved coarse mesh capability. This effort is underway and some progress has been made to adapt an existing finite element nodal diffusion code to the analysis of the SESSR. Static calculations at BOC have been performed using this code and the results appear to be quite acceptable. Effort is now being expended to incorporate depletion-dependent cross sections into this code, along with homogenization techniques including discontinuity factors.

Task 2.6. Optimal fuel depletion strategy. As the first step in this task, our effort has concentrated on developing global fuel depletion capability, with accurate representation of SSCR movement. As summarized in Section 4.6, the algorithm has been successfully tested, but further effort will be required to determine optimal fuel depletion strategy.

Task 3. Verification of SESSR design for PWR use. B\&W Fuel Company has performed neutronics analyses for representative SESSR configurations using the CASMO- 3 code for comparison with the CPM- 2 and VIM codes. A report on this effort has been attached as Appendix A to this report. An additional task involving thermalhydraulic analysis of our SESSR designs was not completed, in favor of the above effort on the neutronics comparison. 
Finally, the progress made during the course of the project has also been reported at various conferences and technical meetings, and the papers are listed below:

(1) J. L. Vujic and W. R. Martin, "Global Restructuring of the CPM-2 Algorithm for Vector and Parallel Processing," Trans. Am. Nucl. Soc. 60, 543-544 (1989).

(2) R. E. Grove, J. C. Lee, and W. R. Martin, "Preliminary Design of a SlightlyEnriched Spectral Shift Reactor," Trans. Am. Nucl. Soc. 60, 634-635 (1989).

(3) J. C. Lee, W. R. Martin, and M. C. Edlund, "Improved Fuel Utilization with a Slightly-Enriched Spectral Shift Reactor," presented at the IAEA Technical Committee Meeting on Technical and Economic Aspects of High Converters, Nuremberg, Germany (1990).

(4) R. E. Grove, W. R. Martin, J. C. Lee, A. Oukebdane, and M.C. Edlund, "Preliminary Design and Analysis of a Slightly-Enriched Spectral Shift Reactor," Proceedings of the International Conference on the Physics of Reactors: Operation, Design, and Computation, Marseille, France (1990).

(5) J. L. Vujic and W. R. Martin, "Two-Dimensional Collision Probability Method with Anisotropic Scattering for Vector and Parallel Processing," Proceedings of the International Conference on the Physics of Reactors: Operation, Design, and Computation, Marseille, France (April 1990).

(6) J. L. Vujic and W. R. Martin, "Vectorization and Parallelization of the CPM-2 Assembly Transport Code," 3rd International Seminar on Finite Element and Allied Methods in Radiation Transport : Shielding, Reactor Physics, and Geophysics Applications, Imperial College, London (1990).

(7) A. Oukebdane and W.R. Martin, "The Coarse Mesh Heterogeneous Response Matrix Method for Reactor Analysis," accepted for presentation at the Winter Meeting of the American Nuclear Society, San Francisco, CA (1991).

\section{Conclusions}

As the project evolved during the past three years, several of the tasks in the original proposal have been set aside and others were added, due to changing priorities in our SESSR design effort, and the limitations (or acceptability) of our existing calculational methods were identified. We are continuing our effort to follow through a number of the research topics generated during the project, since many are suitable for doctoral research. 
The following conclusions represent the principal results of our three-year effort, and are based on the detailed discussion in the preceding sections.

- Our SESSR design evolved from an initial attempt to design a tight lattice configuration, which necessitated a hexagonal rod array, to a semi-tight lattice achievable with a regular square geometry. The overall advantages of the square lattice were compelling. It is significant that other research groups involved with the development of advanced converter reactors have begun to accept the overall superiority of semi-tight lattice designs similar to our final SESSR design.

- Our final design shows that an increase of $17 \sim 20 \%$ in fuel resource utilization can be achieved through the SESSR concept.

- The SESSR design incorporates relatively minor perturbations to the thermal-hydraulic design of conventional PWRs, with the increased pressure drop associated with the relatively tighter lattice being the principal effect. However, the relative effect on the overall pressure drop is considered to be minimal, and less than what would be obtained with a conventional tight lattice $\mathrm{ACR}$ configuration.

- The SESSR design retains the proven safety characteristics of conventional PWRs, including a negative MTC at BOC, which is nearly impossible to ensure with the tight lattice designs.

- The SESSR design avoids the use of burnable absorbers, which decreases the overall complexity and cost of the nuclear design.

- Although the mechanical design of the SESSR design was not considered, the need to incorporate SSCRs into the reactor is a complicating feature. This should be examined in some detail before final conclusions are made concerning the economic viability of this concept. This may mitigate the advantages of the longer fuel cycle and the elimination of burnable absorbers. 


\section{References}

[1] W. R. Martin, J. C. Lee, and M. C. Edlund, "The Slightly-Enriched Spectral Shift Control Reactor," Progress Report for the Period September 30, 1988 - May 31, 1989, DOE/ER/12809-1 (June 1989).

[2] W. R. Martin, J. C. Lee, and M. C. Edlund, "The Slightly-Enriched Spectral Shift Control Reactor," Progress Report for the Period June 1, 1989 - May 31, 1990, DOE/ER/12809-2 (June 1990).

[3] W. R. Martin, J. C. Lee, E.W. Larsen, and M. C. Edlund, "The Slightly-Enriched Spectral Shift Control Reactor," Progress Report for the Period June 1, 1990 - April 30, 1991, DOE/ER/12809-3 (April 1991).

[4] M. C. Edlund, "High Conversion Ratio Plutonium Recycle in Pressurized Water Reactors," Ann. Nucl. Energy, 2, 801 (1975).

[5] J. Bergeron, et al., "The French Neutronic Program Addressing the Requirements of Future Pressurized Water Reactors," Nucl. Tech., 80, 269 (1988).

[6] Y. Ronen and M. J. Leibson, "Analysis of ${ }^{235} \mathrm{U}-\mathrm{Pu}-{ }^{238} \mathrm{U}-$ Fueled Tight-Lattice Water Reactors," Nucl. Tech., 80, 216 (1988).

[7] E. Saji, et al., "Feasibility Studies of High Conversion Pressurized Water Reactors with Semitight Core Configurations," Nucl. Tech., 80, 18 (1988).

[8] G. J. Schlosser, H.-D. Berger, M. Schatz, and K. Thieme, " Nuclear Core Design Studies for a Tight Lattice PWR," presented at the IAEA Technical Committee Meeting on Technical and Economic Aspects of High Converters, Nuremberg, Germany (1990).

[9] D. B. Jones, "ARMP-02 Documentation, Part II, Chapter 6 -- CPM-2 Computer Code Manual," EPRI NP-4574-CCM, Part II, Ch. 6, Volumes 1, 2, and 3, Electric Power Research Institute (1987).

[10] "Babcock \&Wilcox Standard Safety Analysis Report," B-SAR-205, Babcock \& Wilcox Fuel Company (1976).

[11] "Millstone Nuclear Power Station Unit 3 Final Safety Analysis Report," U.S. Nuclear Regulatory Commission Docket Number 50-423, Amendment 13 (1985).

[12] W. W. Little, Jr. and R. W. Hardie, "2DB - User's Manual - Revision I," BNWL831 Rev. 1, Battelle Pacific Northwest Laboratory (1969).

[13] H. W. Graves, "Michigan Thermal Hydraulic Analysis Code," Unpublished Note, Department of Nuclear Engineering, University of Michigan (1972).

[14] L. S. Tong, Boiling Heat Transfer and Two-Phase Flow, John Wiley and Sons, Inc., New York (1966). 
[15] Babcock and Wilcox, et. al., "Technical Feasibility of a PWR Design with a Low Water Volume Fraction Lattice," EPRI-NP-1833, Appendix A, Electric Power Research Institute (1981).

[16] R. Hornes, B\&W Fuel Company, private communication to J. C. Lee, June, 1991.

[17] "Nuclear Energy Cost Data Base," DOE/NE-0095, U. S. Department of Energy (1988).

[18] R. F. Barry, "LEOPARD - A Spectrum Dependent Non-Spatial Depletion Code for the IBM-7094," WCAP-3269-26, Westinghouse Electric Corp. (1963).

[19] R. W. Hardie and W. W. Little, Jr., "3DB, A Three-Dimensional Diffusion Theory Burnup Code," BNWL-1264, Battelle Pacific Northwest Laboratory (1970).

[20] L. J. Milton and R. E. Prael, "A User's Manual for the Monte Carlo Code, VIM," FRA Technical Memorandum No. 84, Argonne National Laboratory (1976).

[21] M. Edenius and A. Ahlin, "CASMO-3 User's Manual," STUDSVIK/NFA-86/7, Studsvik Company (1986).

[22] R. Seiler et al., "Investigation of the Void Coefficient and Other Integral Parameters in the PROTEUS-LWHCR Phase II Program," Nucl. Tech., 80, 311 (1988).

[23] E. Hettergott, R. Chawla, and K. Gmur, "Analysis of Test Lattice Experiments in the Light Water High-Conversion Reactor PROTEUS," EPRI-NP-3190, Electric Power Research Institute (1983).

[24] N. M. Greene and C. W. Craven, Jr., "XSDRN : A Discrete Ordinates Spectral Averaging Code," ORNL-TM-2500, Oak Ridge National Laboratory (1969).

[25] R. M. Westfall, et al., "NITAWL-S : Resonance Self-Shielding by the Nordheim Method," ORNL/NUREG/CSD-2/V2, Oak Ridge National Laboratory (1981).

[26] W. B. Terney, "Albedo-Adjusted Fast-Neutron Diffusion Coefficients in Reactor Reflectors," Nucl. Sci. Eng., 57, 239 (1975).

[27] T. England, W.B. Wilson, and M.G. Stamatelatos, "Fission Product Data for Thermal Reactors -- User's Manual for EPRI-CINDER Code and Data," EPRI-NP356, Part 1 (1976).

[28] W. Bernatt, Y. Ishiguro, E. Sartori, J. Stepanek, and M. Takano, "Advances in the Analysis of the NEACRP High Conversion LWR Benchmark Problems," Proc. Int. Conf. Physics of Reactors, I-54, Marseille, France (1990).

[29] N. E. Patino, M. J. Abbate, and M. M. Sbaffoni, "Evaluation of Some Resonance Self-Shielding Procedures Employed in High Conversion Light Water Reactor Design," Proc. Int. Conf. Physics of Reactors, PI-42, Marseille, France (1990).

[30] D. E. Cullen, "Application of the Probability Table Method to Multigroup Calculations of Neutron Transport", Nucl. Sc. Eng., 55, 387 (1974). 
[31] M. Edenius, K. Ekberg, and H. Haggblom, "ARMP-02 Documentation, Part II, Chapter 4: The EPRI-CPM Data Library," EPRI NP-4574-CCM, Part II, Ch. 4, Electric Power Research Institute (1988).

[32] M. Edenius, C. Gragg, "CASLIB User's Manual, Version 1.3," STUDSVIK/NFA89/13, Studsvik of America, Inc. (1989).

[33] D. V. Altiparmakov and D. Tomasevic, "Variational Formulation of a Higher Order Nodal Diffusion Method," Nucl. Sci. Eng., 105, 256 (1990).

[34] K. Koebke and M. R. Wagner, "The Determination of Pin Power Distribution in a Reactor Core on the Basis of Nodal Coarse Mesh Calculations," Atomkernenergie, 30,136 (1977).

[35] M. Edenius, K. S. Smith, and D. M. Ver Plank, "Recent Developments in the MICBURN/CASMO/SIMULATE LWR Analysis Package," Proc. Am. Nucl. Soc. Topical Meeting on Advances in Fuel Management, Pinehurst, NC (1986).

[36] K. S. Smith, "Assembly Homogenization Techniques for Light Water Reactor Analysis," Prog. Nucl. Energy, 17, 303 (1986).

[37] H. Nakata and W. R. Martin, "The Finite Element Response Matrix Method," Nucl. Sci. Eng., 85, 289 (1983).

[38] J. A. Rathkopf and W. R. Martin, "The Finite Element Response Matrix Method for the Solution of the Neutron Transport Equation,"Prog. Nucl. Energy, 18, 23 (1986).

[39] J. A. Rathkopf, L. J. Lorence, and W. R. Martin, "The Explicitly-Interfaced Method and the Response Matrix Method: Two Methods for the Solution of the Transport Equation," Proc. Int. Topical Meeting on Advances in Reactor Physics, Mathematics, and Computation, Vol. 2, 1021, Paris (1987).

[40] A. Oukebdane and W.R. Martin, "The Heterogeneous Response Matrix Method," accepted for presentation at the Winter Meeting of the American Nuclear Society, San Francisco, CA (1991).

[41] A. Hébert, "Application of the Hermite Method for Finite Element Reactor Calculations," Nucl. Sci. Eng., 91, 34 (1985).

[42] J. L. Vujic and W. R. Martin, "Two-Dimensional Collision Probability Method with Anisotropic Scattering for Vector and Parallel Processing," Proc. Int. Conf. Physics of Reactors, PIV-104, Marseille, France (1990).

[43] J. L. Vujic and W. R. Martin, "Vectorization and Parallelization of the CPM-2 Assembly Transport Code," 3rd International Seminar on Finite Element and Allied Methods in Radiation Transport : Shielding, Reactor Physics, and Geophysics Applications, Imperial College, London (1990). 
CASMO3 - CPM2 COMPARISONS

FOR SPECTRAL SHIFT LATTICES

\author{
Report Submitted to \\ the University of Michigan \\ on work done as a \\ subcontractor under \\ Department of Energy Grant \\ DE-FG07-883412809 \\ (Purchase Order Z18412)
}

August 20, 1990

Submitted by

B\&W Fuel Company

P.O. Box 10935

Lynchburg, Virginia 24506 
The spectral shift lattice cases computed by the University of Michigan (UM) using the CPM2 code and the cases computed by the Babcock \& Wilcox Fuel Company (BWFC) using the CASMO3 code are identified as follows:

\begin{tabular}{|c|c|c|}
\hline $\begin{array}{l}\text { UM } \\
\text { ID }\end{array}$ & $\begin{array}{l}\text { BWFC } \\
\text { ID }\end{array}$ & $\begin{array}{l}\text { UM CASE } \\
\text { DESCRIPTION }\end{array}$ \\
\hline- & $\mathrm{C} 44 \mathrm{Ai}$ & TTL SSR $(4 \times 4), V F / V M=1.2,2.5 \mathrm{w} / 0, \mathrm{SSC}$ in. \\
\hline - & $\mathrm{C} 44 \mathrm{Bi}$ & TTL SSR $(4 \times 4), V F / V M=0.8,2.5 \mathrm{w} / 0$, SSC withdrawn \\
\hline CIIBW & $\mathrm{CIIBWi}$ & TTL SSR ( $17 \times 17), 104 \mathrm{SSC}$ rods out, $2.5 \mathrm{w} / 0$, HFP. \\
\hline$C \perp 1 B D$ & CIIBDi & TTL SSR $(27 \times 17), 104 \mathrm{SSC}$ rods in, $2.5 \mathrm{w} / 0$, HFP. \\
\hline ALTSSR & C316i & $\begin{array}{l}\text { TTL SSR }(17 \times 17), 80 \text { SSCR, No CR, } 2.5 \text { wt\%, HFP, } 0 \\
\text { ppm, SSCR in, Case 3.16. }\end{array}$ \\
\hline
\end{tabular}


1. BWFC ID C44Ai (4X4 SSC in)

REACTIVITY AND 2-GROUP CROSS SECTIONS

$\begin{array}{llll}\text { Parameter } & \text { CASMO3 } & \text { CPM2 } & \text { CASMO/CP } \\ \text { k-infinite (2D COXY) } & 1.1151 & 1.1075 & 1.0069 \\ \text { Group 1 X-SECT } & & & \\ \text { Diffusion } & 1.5162 & 1.5224 & 0.9959 \\ \text { Absorption } & 0.0094125 & 0.0096211 & 0.9783 \\ \text { Nu-fission } & 0.0064086 & 0.0063029 & 1.0168 \\ \text { Removal } & 0.0075045 & 0.0077519 & 0.9681 \\ & & & \\ \text { Group 2 X-SECT } & 0.55848 & 0.55978 & 0.9976 \\ \text { Diffusion } & 0.081893 & 0.081611 & 1.0035 \\ \text { Absorption } & 0.13766 & 0.13687 & 1.0058 \\ \text { Nu-fission } & 0.0011492 & 0.0011627 & 0.9884 \\ \text { Removal } & & & \end{array}$

RELATIVE POWER DISTRIBUTION

\begin{tabular}{|c|c|c|c|c|}
\hline $\begin{array}{l}0.988 \\
0.586\end{array}$ & & & & \\
\hline $\begin{array}{l}1.006 \\
1.006\end{array}$ & SSCR & & & \\
\hline $\begin{array}{l}1.006 \\
1.008\end{array}$ & SSCR & SSCR & & \\
\hline $\begin{array}{l}0.988 \\
0.987\end{array}$ & $\begin{array}{l}1.006 \\
1.008\end{array}$ & $\begin{array}{l}1.006 \\
1.006\end{array}$ & $\begin{array}{l}0.988 \\
0.986\end{array}$ & $\begin{array}{l}=\text { CASMO } 3 \\
=\text { CPM } 2\end{array}$ \\
\hline
\end{tabular}

For this case (4X4 with SSC rods in) the CASMO3 2D COXY eigenvalue is about 0.698 higher than CPM2 and the hot pin power peak is about $0.2 \%$ lower than CPM2. The agreement between the codes is quite good considering the extreme heterogeneus nature of the lattice. 
2. BWFC ID C44Bi $(4 \times 4$ SSC Out $)$

REACTIVITY AND 2-GROUP CROSS SECTIONS

$\begin{array}{llll}\text { Parameter } & \text { CASMO3 } & \text { CPM2 } & \text { CASMO/CP } \\ \text { k-infinite (2D COXY) } & 1.2117 & 1.2139 & 0.9982 \\ \text { Group 1 X-SECT } & & & \\ \quad \text { Diffusion } & 1.3470 & 1.3502 & 0.9976 \\ \text { Absorption } & 0.0097310 & 0.0101633 & 0.9575 \\ \text { Nu-fission } & 0.0067824 & .0067393 & 1.0064 \\ \text { Removal } & 0.012483 & 0.013230 & 0.9435 \\ & & & \\ \text { Group 2 X-SECT } & 0.39582 & 0.39866 & 0.9929 \\ \text { Diffusion } & 0.085592 & 0.087246 & 0.9810 \\ \text { Absorption } & 0.14044 & 0.14324 & 0.9805 \\ \text { Nu-fission } & 0.0009449 & 0.0009616 & 0.9826 \\ \text { Removal } & & \end{array}$

RELATIVE POWER DISTRIBUTION

\begin{tabular}{|c|c|c|c|c|}
\hline $\begin{array}{l}0.960 \\
0.953\end{array}$ & & & & \\
\hline $\begin{array}{l}1.020 \\
1.020\end{array}$ & SSCR & & & \\
\hline $\begin{array}{l}1.020 \\
1.026\end{array}$ & SSCR & SSCR & & \\
\hline $\begin{array}{l}0.960 \\
0.956\end{array}$ & $\begin{array}{l}1.020 \\
1.026\end{array}$ & $\begin{array}{l}1.020 \\
1.020\end{array}$ & $\begin{array}{l}0.960 \\
0.953\end{array}$ & $\begin{array}{l}=\text { CASMO3 } \\
=\text { CPM2 }\end{array}$ \\
\hline
\end{tabular}

For this case ( $4 \times 4$ with SSC rods out) the CASMO3 $2 \mathrm{D}$ COXY eigenvalue is about $0.18 \%$ lower than SPM2 and the hot pin power peak is about $0.58 \%$ lower than CPM2. Again the agreement between the codes is quite good. 
3. BWFC ID C11BWi $(17 \times 17,104$ SSC Rods out $)$

REACTIVITY AND 2-GROUP CROSS SECTIONS

$\begin{array}{llll}\text { Parameter } & \text { CASMO3 } & \text { CPM2 } & \text { CASMO/CPM } \\ \text { k-infinite (2D COXY) } & 1.2973 & 1.2950 & 1.0018 \\ \text { Group 1 X-SECT } & & & \\ \text { Diffusion } & 1.4570 & 1.4938 & 0.9754 \\ \text { Absorption } & 0.0076799 & 0.0076223 & 1.0076 \\ \text { Nu-fission } & 0.0052342 & 0.0050002 & 1.0468 \\ \text { Removal } & 0.017295 & 0.017320 & 0.9986 \\ \text { Group 2 X-SECT } & & & \\ \text { Diffusion } & 0.38303 & 0.37595 & 1.0188 \\ \text { Absorption } & 0.060937 & 0.059792 & 1.0191 \\ \text { Nu-fission } & 0.096590 & 0.094253 & 1.0248 \\ \text { Removal } & 0.0012611 & 0.0011952 & 1.0511\end{array}$




\section{RELATIVE POWER DISTRIBUTION}

\begin{tabular}{|c|c|c|c|c|c|c|c|c|}
\hline IC & & & & & & & & \\
\hline $\begin{array}{l}0.966 \\
0.951\end{array}$ & $\mathrm{H}_{2} \mathrm{O}$ & & & & & & & \\
\hline $\begin{array}{l}0.952 \\
0.942\end{array}$ & $\begin{array}{l}0.961 \\
0.951\end{array}$ & $\begin{array}{l}0.998 \\
0.990\end{array}$ & & & & & & \\
\hline $\mathrm{H}_{2} \mathrm{O}$ & $\begin{array}{l}1.011 \\
1.003\end{array}$ & $\mathrm{H}_{2} \mathrm{O}$ & $\mathrm{H}_{2} \mathrm{O}$ & & & & & \\
\hline $\begin{array}{l}1.009 \\
1.006\end{array}$ & $\mathrm{H}_{2} \mathrm{O}$ & $\begin{array}{l}1.028 \\
1.022\end{array}$ & $\begin{array}{l}1.010 \\
1.006\end{array}$ & $\mathrm{H}_{2} \mathrm{O}$ & & & & \\
\hline $\begin{array}{l}0.978 \\
0.975\end{array}$ & $\begin{array}{l}0.996 \\
0.988\end{array}$ & $\mathrm{H}_{2} \mathrm{O}$ & $\begin{array}{l}0.991 \\
0.987\end{array}$ & $\begin{array}{l}0.982 \\
0.978\end{array}$ & $\mathrm{H}_{2} \mathrm{O}$ & & & \\
\hline $\mathrm{H}_{2} \mathrm{O}$ & $\begin{array}{l}1.004 \\
1.000\end{array}$ & $\begin{array}{l}0.996 \\
0.993\end{array}$ & $\mathrm{H}_{2} \mathrm{O}$ & $\begin{array}{l}0.981 \\
0.976\end{array}$ & $\begin{array}{l}0.962 \\
0.959\end{array}$ & $\begin{array}{l}0.980 \\
0.981\end{array}$ & & \\
\hline $\begin{array}{l}1.072 \\
1.082\end{array}$ & $\mathrm{H}_{2} \mathrm{O}$ & $\begin{array}{l}1.009 \\
1.010\end{array}$ & $\begin{array}{l}0.993 \\
0.995\end{array}$ & $\mathrm{H}_{2} \mathrm{O}$ & $\begin{array}{l}1.008 \\
1.007\end{array}$ & $\mathrm{H}_{2} \mathrm{O}$ & $\begin{array}{l}0.997 \\
1.010\end{array}$ & $\begin{array}{l}=\text { CASMO } 3 \\
=\mathrm{CPM} 2\end{array}$ \\
\hline $\mathrm{H}_{2} \mathrm{O}$ & $\begin{array}{l}1.082 \text { * } \\
1.100\end{array}$ & $\mathrm{H}_{2} \mathrm{O}$ & $\begin{array}{l}0.992 \\
1.004\end{array}$ & $\begin{array}{l}1.007 \\
1.014\end{array}$ & $\mathrm{H}_{2} \mathrm{O}$ & $\begin{array}{l}1.010 \\
1.019\end{array}$ & $\begin{array}{l}1.001 \\
1.019\end{array}$ & $\mathrm{H}_{2} \mathrm{O}$ \\
\hline
\end{tabular}

For this case ( $17 \times 17$, SSC rods out) the CASMO3 2D COXY eigenvalue is about $0.18 \%$ higher than CPM2 and the hot pin power peak is about $1.64 \%$ lower than CPM2. Overall agreement is quite good. 
4. BWFC ID CIIBDi $(17 \times 17,104$ SSC Rods in)

REACTIVITY AND 2-GROUP CROSS SECTIONS

$\begin{array}{llll}\text { Parameter } & \text { CASMO3 } & \text { CPM2 } & \text { CASMO/CP } \\ \text { k-infinite (2D COXY) } & 1.2225 & 1.2220 & 1.0004 \\ \text { Group I X-SECT } & & & \\ \text { Diffusion } & 1.7958 & 1.8328 & 0.9798 \\ \text { Absorption } & 0.0072496 & 0.0072374 & 1.0017 \\ \text { Nu-fission } & 0.0048981 & 0.0047382 & 1.0337 \\ \text { Removal } & 0.0098221 & 0.0100502 & 0.9773 \\ & & & \\ \text { Group 2 X-SECT } & 0.57589 & 0.56330 & 1.0224 \\ \text { Diffusion } & 0.056582 & 0.055887 & 1.0124 \\ \text { Absorption } & 0.092867 & 0.091316 & 1.0170 \\ \text { Nu-fission } & 0.0012728 & 0.0012082 & 1.0535 \\ \text { Removal } & & \end{array}$




\section{RELATIVE POWER DISTRIBUTION}

\begin{tabular}{|c|c|c|c|c|c|c|c|c|}
\hline IC & & & & & & & & \\
\hline $\begin{array}{l}0.986 \\
0.972\end{array}$ & SSC & & & & & & & \\
\hline $\begin{array}{l}0.977 \\
0.964\end{array}$ & $\begin{array}{l}0.979 \\
0.967\end{array}$ & $\begin{array}{l}0.992 \\
0.979\end{array}$ & & & & & & \\
\hline SSC & $\begin{array}{l}0.997 \\
0.985\end{array}$ & ssc & SSC & & & & & \\
\hline $\begin{array}{l}0.996 \\
0.987\end{array}$ & ssc & $\begin{array}{l}1.001 \\
0.991\end{array}$ & $\begin{array}{l}0.995 \\
0.986\end{array}$ & SSC & & & & \\
\hline $\begin{array}{l}0.988 \\
0.982\end{array}$ & $\begin{array}{l}0.993 \\
0.984\end{array}$ & SSC & $\begin{array}{l}0.991 \\
0.984\end{array}$ & $\begin{array}{l}0.988 \\
0.984\end{array}$ & SSC & & & \\
\hline SSC & $\begin{array}{l}0.998 \\
0.993\end{array}$ & $\begin{array}{l}0.995 \\
0.991\end{array}$ & SSC & $\begin{array}{l}0.992 \\
0.989\end{array}$ & $\begin{array}{l}0.986 \\
0.986\end{array}$ & $\begin{array}{l}0.997 \\
1.003\end{array}$ & & \\
\hline $\begin{array}{l}1.022 \\
1.025\end{array}$ & ssc & $\begin{array}{l}1.005 \\
1.006\end{array}$ & $\begin{array}{l}0.999 \\
1.001\end{array}$ & ssc & $\begin{array}{l}1.009 \\
1.013\end{array}$ & SSC & $\begin{array}{l}1.010 \\
1.026\end{array}$ & $\begin{array}{l}=\text { CASMO } 3 \\
=\text { CPM } 2\end{array}$ \\
\hline SSC & $\begin{array}{l}1.032 \\
1.044\end{array}$ & SSC & $\begin{array}{l}1.006 \\
1.019\end{array}$ & $\begin{array}{l}1.012 \\
1.026\end{array}$ & SSC & $\begin{array}{l}1.017 \\
1.034\end{array}$ & $\begin{array}{l}1.020^{\star} \\
1.045\end{array}$ & SSC \\
\hline
\end{tabular}

For this case ( $17 \times 17$, SSC rods in) the CASMO3 2D COXY eigenvalue is about $0.04 \%$ higher than CPM2 and the hot pin power peak is about $2.39 \%$ lower than CPM2. CASMO3 consistently computes less power variation (flatter disicibution) than CPM2. 
5. BWFC ID C316i $(17 \times 17,80$ SCR in, depletion)

REACTIVITY PLUS U235/U238 AND PU239/U238 ATOM RATIOS VERSUS EXPOSURE

\begin{tabular}{|c|c|c|c|c|c|c|c|c|c|}
\hline \multirow{2}{*}{$\begin{array}{l}\text { OSURE } \\
\text { D/MTU) }\end{array}$} & \multicolumn{3}{|c|}{$k$-infinite (2D COXY) } & \multicolumn{3}{|c|}{$\mathrm{U} 235 / \mathrm{U} 238 \times 100$} & \multicolumn{3}{|c|}{ PU239/U238 $\times 100$} \\
\hline & CASMO3 & CPM2 & CASMO/CPM & CASMO3 & CPM2 & CASMO/CPM & CASMO3 & CPM2 & CASMO/CPM \\
\hline 0 & 1.1981 & 1.1961 & 1.0017 & 2.5974 & 2.5969 & 1.0002 & 0.0000 & 0.0000 & 1.0000 \\
\hline 0.1 & 1.1572 & 1.1542 & 1.0026 & 2.5855 & 2.5849 & 1.0002 & 0.0029 & 0.0081 & 0.3580 \\
\hline 0.5 & 1.1481 & 1.1465 & 1.0014 & 2.5386 & 2.5378 & 1.0003 & 0.0315 & 0.0397 & 0.7935 \\
\hline 1.0 & 1.1419 & 1.1407 & 1.0011 & 2.4820 & 2.4809 & 1.0004 & 0.0685 & 0.0767 & 0.8931 \\
\hline 2.0 & 1.1293 & 1.1283 & 1.0009 & 2.3749 & 2.3733 & 1.0007 & 0.1355 & 0.1435 & 0.9443 \\
\hline 4.0 & 1.1021 & 1.1011 & 1.0009 & 2.1803 & 2.1777 & 1.0012 & 0.2468 & 0.2546 & 0.9694 \\
\hline 8.0 & 1.0545 & 1.0538 & 1.0007 & 1.8498 & 1.8451 & 1.0025 & 0.4117 & 0.4195 & 0.9814 \\
\hline 12.0 & 1.0180 & 1.0171 & 1.0009 & 1.5770 & 1.5705 & 1.0041 & 0.5293 & 0.5369 & 0.9858 \\
\hline 16.0 & 0.9877 & 0.9869 & 1.0008 & 1.3481 & 1.3401 & 1.0060 & 0.6176 & 0.6249 & 0.9883 \\
\hline 20.0 & 0.9620 & 0.9612 & 1.0008 & 1.1542 & 1.1450 & 1.0080 & 0.6865 & 0.6932 & 0.9903 \\
\hline 24.0 & 0.9392 & 0.9388 & 1.0004 & 0.9893 & 0.9790 & 1.0105 & 0.7421 & 0.7480 & 0.9921 \\
\hline 28.0 & 0.9196 & 0.9190 & 1.0006 & 0.8487 & 0.8376 & 1.0133 & 0.7883 & 0.7931 & 0.9939 \\
\hline 32.0 & 0.9017 & 0.9014 & 1.0003 & 0.7286 & 0.7170 & 1.0162 & 0.8279 & 0.8312 & 0.9960 \\
\hline 36.0 & 0.8858 & 0.8857 & 1.0001 & 0.6259 & 0.6140 & 1.0194 & 0.8625 & 0.8640 & 0.9983 \\
\hline
\end{tabular}

For this depletion case the eigenvalues agree to better than $0.26 \%$ at all exposures. There appears to be a difference in the buildup of plutonium at low exposures with the differences decreasing with increasing exposure. Conversely, the differences in U235 concentrations increase with exposure. At 36.0 GWD/MTU the CASMO 3 predicts $1.94 \%$ more U235 and $0.17 \%$ less PU239 than does CPM2. CASMO3 consistently predicts lower power peaks than CPM2. By examining the relative power distributions on the next three pages, it is seen that the peak pin power computed by CASMO3 is $2.56 \%, 2.57 \%$, and $2.21 \%$ lower at BOC, $16 \mathrm{GWD} / \mathrm{MTU}$, and $32 \mathrm{MWD} / \mathrm{MTW}$, respectively, than those computed by CPM2. The 2-group and 4-group cross sections versus exposure are given in the CASMO3 outputs. 


\section{RELATIVE POWER DISTRIBUTION AT BOC}

\begin{tabular}{|c|c|c|c|c|c|c|c|c|}
\hline IC & & & & & & & & \\
\hline $\begin{array}{l}1.005 \\
0.993\end{array}$ & SSC & & & & & & & \\
\hline $\begin{array}{l}0.988 \\
0.977\end{array}$ & $\begin{array}{l}0.996 \\
0.983\end{array}$ & $\begin{array}{l}0.986 \\
0.976\end{array}$ & & & & & & \\
\hline $\begin{array}{l}1.006 \\
0.994\end{array}$ & SSC & $\begin{array}{l}0.994 \\
0.983\end{array}$ & SSC & & & & & \\
\hline SSC & $\begin{array}{l}1.007 \\
0.996\end{array}$ & $\begin{array}{l}0.987 \\
0.980\end{array}$ & $\begin{array}{l}0.994 \\
0.984\end{array}$ & $\begin{array}{l}0.983 \\
0.977\end{array}$ & & & & \\
\hline $\begin{array}{l}1.007 \\
0.998\end{array}$ & SSC & $\begin{array}{l}1.006 \\
0.998\end{array}$ & SSC & $\begin{array}{l}0.994 \\
0.990\end{array}$ & $\begin{array}{l}0.984 \\
0.983\end{array}$ & & & \\
\hline $\begin{array}{l}0.982 \\
0.976\end{array}$ & $\begin{array}{l}0.996 \\
0.989\end{array}$ & SSC & $\begin{array}{l}1.007 \\
1.001\end{array}$ & SSC & $\begin{array}{l}0.998 \\
0.997\end{array}$ & SSC & & \\
\hline $\begin{array}{l}0.987 \\
0.986\end{array}$ & $\begin{array}{l}0.984 \\
0.983\end{array}$ & $\begin{array}{l}0.994 \\
0.995\end{array}$ & $\begin{array}{l}1.002 \\
1.003\end{array}$ & $\begin{array}{l}1.001 \\
1.005\end{array}$ & $\begin{array}{l}1.003 \\
1.010\end{array}$ & $\begin{array}{l}0.999 \\
1.007\end{array}$ & $\begin{array}{l}1.001 \\
1.016\end{array}$ & $\begin{array}{l}=\mathrm{CASMO} 3 \\
=\mathrm{CPM} 2\end{array}$ \\
\hline SSC & $\begin{array}{l}1.001 \\
1.011\end{array}$ & $\begin{array}{l}1.006 \\
1.019\end{array}$ & SSC & $\begin{array}{l}1.024 \\
1.040\end{array}$ & SSC & $\begin{array}{l}1.015 \\
1.035\end{array}$ & $\begin{array}{l}1.026^{\star} \\
1.053\end{array}$ & SSC \\
\hline
\end{tabular}

${ }^{\star}$ peak pin difference $=2.56 \%$ 


\section{RELATIVE POWFR DISTRIBUTION AT 16.0 GWD/MTU}

\begin{tabular}{|c|c|c|c|c|c|c|c|c|}
\hline IC & & & & & & & & \\
\hline $\begin{array}{l}1.004 \\
0.996\end{array}$ & SSC & & & & & & & \\
\hline $\begin{array}{l}0.994 \\
0.983\end{array}$ & $\begin{array}{l}0.992 \\
0.979\end{array}$ & $\begin{array}{l}1.004 \\
0.995\end{array}$ & & & & & & \\
\hline $\begin{array}{l}1.005 \\
0.996\end{array}$ & SSC & $\begin{array}{l}0.991 \\
0.981\end{array}$ & SSC & & & & & \\
\hline SSC & $\begin{array}{l}1.006 \\
0.996\end{array}$ & $\begin{array}{l}0.996 \\
0.989\end{array}$ & $\begin{array}{l}0.991 \\
0.981\end{array}$ & $\begin{array}{l}0.990 \\
0.983\end{array}$ & & & & \\
\hline $\begin{array}{l}1.006 \\
0.999\end{array}$ & SSC & $\begin{array}{l}1.005 \\
0.999\end{array}$ & SSC & $\begin{array}{l}0.992 \\
0.987\end{array}$ & $\begin{array}{l}0.988 \\
0.986\end{array}$ & & & \\
\hline $\begin{array}{l}0.981 \\
0.975\end{array}$ & $\begin{array}{l}0.993 \\
0.987\end{array}$ & SSC & $\begin{array}{l}1.007 \\
1.002\end{array}$ & SSC & $\begin{array}{l}0.996 \\
0.994\end{array}$ & SSC & & \\
\hline $\begin{array}{l}0.983 \\
0.979\end{array}$ & $\begin{array}{l}0.987 \\
0.984\end{array}$ & $\begin{array}{l}0.993 \\
0.992\end{array}$ & $\begin{array}{l}1.007 \\
1.008\end{array}$ & $\begin{array}{l}1.004 \\
1.006\end{array}$ & $\begin{array}{l}1.007 \\
1.012\end{array}$ & $\begin{array}{l}0.998 \\
1.002\end{array}$ & $\begin{array}{l}0.999 \\
1.009\end{array}$ & $\begin{array}{l}=\mathrm{CASMO} 3 \\
=\mathrm{CPM} 2\end{array}$ \\
\hline SSC & $\begin{array}{l}0.999 \\
1.012\end{array}$ & $\begin{array}{l}1.003 \\
1.019\end{array}$ & SSC & $\begin{array}{l}1.002 \\
1.041\end{array}$ & SSC & $\begin{array}{l}1.012 \\
1.032\end{array}$ & $\begin{array}{l}1.022^{\star} \\
1.049\end{array}$ & SSC \\
\hline
\end{tabular}

${ }^{*}$ peak pin difference $=2.57 \%$ 


\begin{tabular}{|c|c|c|c|c|c|c|c|c|}
\hline IC & & & & & & & & \\
\hline $\begin{array}{l}1.003 \\
0.997\end{array}$ & SSC & & & & & & & \\
\hline $\begin{array}{l}0.997 \\
0.987\end{array}$ & $\begin{array}{l}0.991 \\
0.979\end{array}$ & $\begin{array}{l}1.013 \\
1.006\end{array}$ & & & & & & \\
\hline $\begin{array}{l}1.005 \\
0.998\end{array}$ & SSC & $\begin{array}{l}0.990 \\
0.982\end{array}$ & Ssc & & & & & \\
\hline SSC & $\begin{array}{l}1.005 \\
0.997\end{array}$ & $\begin{array}{l}1.001 \\
0.994\end{array}$ & $\begin{array}{l}0.990 \\
0.981\end{array}$ & $\begin{array}{l}0.995 \\
0.989\end{array}$ & & & & \\
\hline $\begin{array}{l}1.005 \\
1.000\end{array}$ & SSC & $\begin{array}{l}1.005 \\
1.000\end{array}$ & SSC & $\begin{array}{l}0.992 \\
0.988\end{array}$ & $\begin{array}{l}0.991 \\
0.989\end{array}$ & & & \\
\hline $\begin{array}{l}0.983 \\
0.977\end{array}$ & $\begin{array}{l}0.993 \\
0.987\end{array}$ & SSC & $\begin{array}{l}1.006 \\
1.003\end{array}$ & SSC & $\begin{array}{l}0.995 \\
0.993\end{array}$ & SSC & & \\
\hline $\begin{array}{l}0.982 \\
0.978\end{array}$ & $\begin{array}{l}0.989 \\
0.986\end{array}$ & $\begin{array}{l}0.993 \\
0.991\end{array}$ & $\begin{array}{l}1.010 \\
1.010\end{array}$ & $\begin{array}{l}1.005 \\
1.006\end{array}$ & $\begin{array}{l}1.008 \\
1.011\end{array}$ & $\begin{array}{l}0.997 \\
0.999\end{array}$ & $\begin{array}{l}0.998 \\
1.004\end{array}$ & $\begin{array}{l}=\text { CASMO } 3 \\
=\text { CPM } 2\end{array}$ \\
\hline ssc & $\begin{array}{l}0.999 \\
1.011\end{array}$ & $\begin{array}{l}1.001 \\
1.016\end{array}$ & SSC & $\begin{array}{l}1.019 \\
1.036\end{array}$ & SSC & $\begin{array}{l}1.008 \\
1.026\end{array}$ & $\begin{array}{l}1.017^{\star} \\
1.040\end{array}$ & SSC \\
\hline
\end{tabular}

${ }^{*}$ peak pin difference $=2.21 \%$ 


\section{DISCUSSION}

Although the 2D COXY $k$-infinities agree quite well for all cases, fundamental mode $k$-infinite values show larger differences. For cases C44Ai and C44Bi, the CASMO fundamental mode $\mathrm{k}$-infinite values are $1.34 \%$ and $1.11 \%$ higher, respectively, than the CPM2 values. Also, for case C44Bi the migration area computed by CASMO3 is $21.5 \%$ larger than that computed by CPM2, while for case C11BWi the CASMO3 computes a migration area $20.2 \%$ smalier than does CPM2. Thus, there appears to be differences in the fundamental mode calculations, and the migration areas may be defined differently. Differences in the important 2group constants range from zero to 5\%, but these differences have lesser effect on lattice reactivity. 

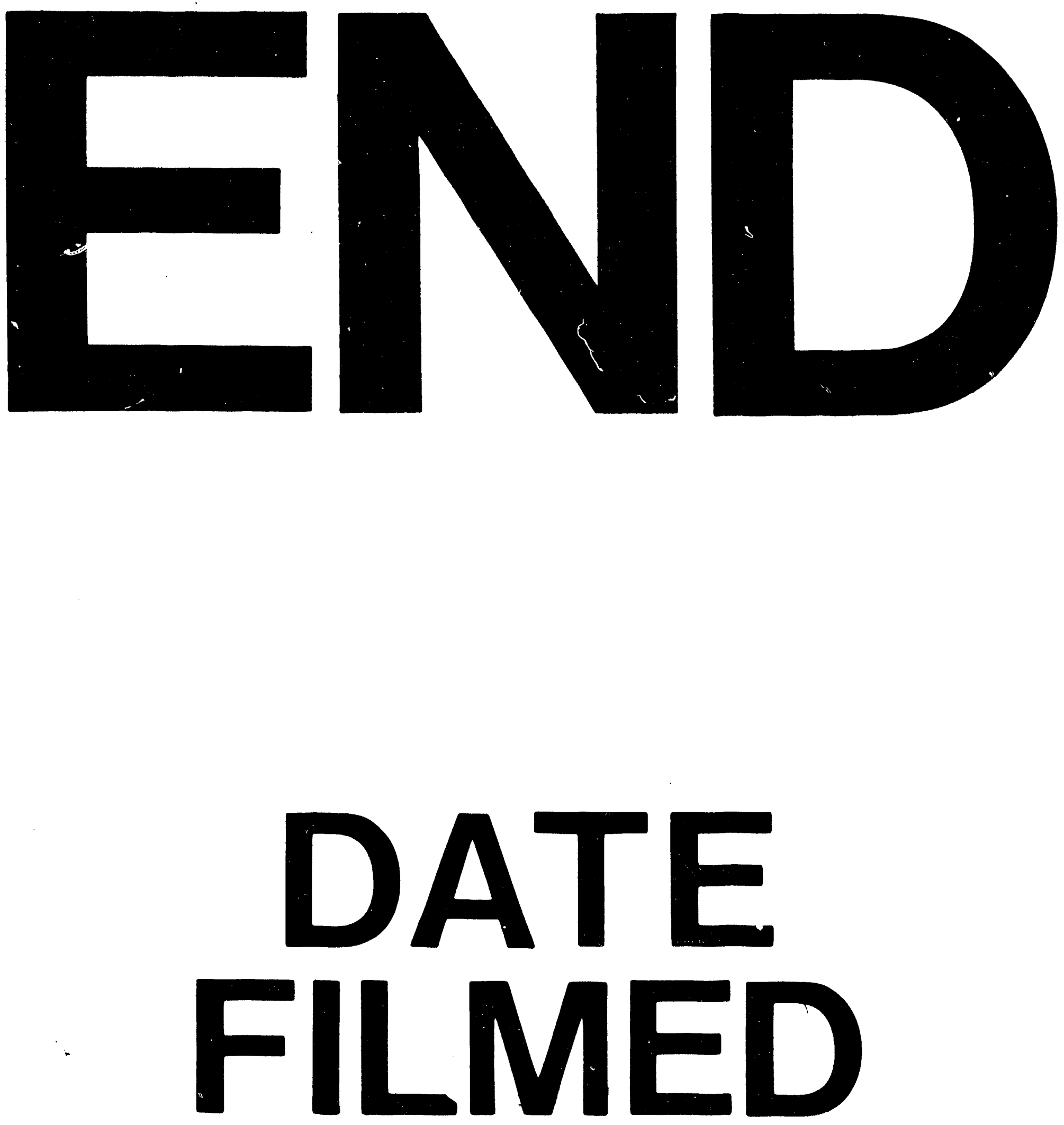

I

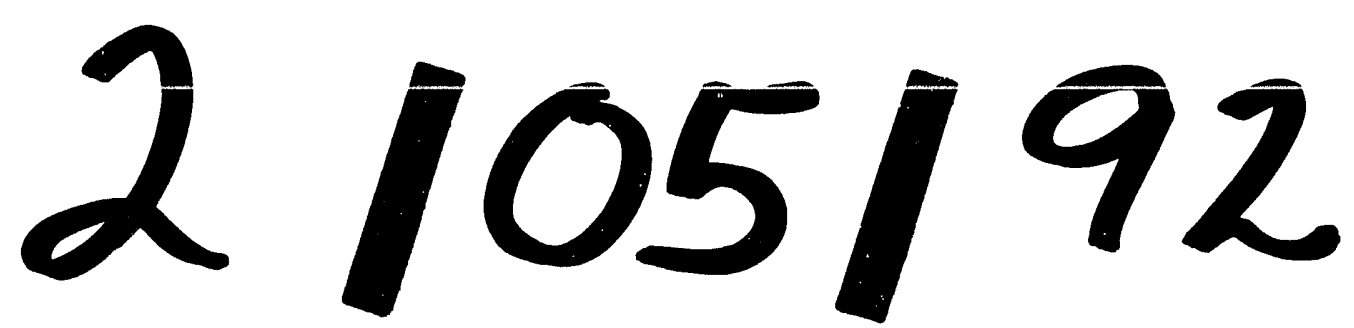




$$
\text { .. }
$$

